\title{
Metal-organic frameworks for active food packaging. A review
}

\author{
Afreen Sultana ${ }^{1} \cdot$ Ajay Kathuria $^{2} \cdot$ Kirtiraj K. Gaikwad $^{1}$ (I) \\ Received: 26 December 2021 / Accepted: 2 January 2022 / Published online: 11 January 2022 \\ (c) The Author(s), under exclusive licence to Springer Nature Switzerland AG 2022
}

\begin{abstract}
Food wastage is a major concern for sustainable health and agriculture. To reduce food waste, classical preservation techniques such as drying, pasteurization, freeze-drying, fermentation, and microwave are available. Nonetheless, these techniques display shortcomings such as alteration of food and taste. Such shortcomings may be solved by active food packaging, which involves the incorporation of active agents into the packaging material. Recently, metal-organic frameworks, a class of porous hybrid supramolecular materials, have been developed as an active agent to extend food shelf life and maintain safety. Here, we review metal-organic frameworks in active packaging as oxygen scavengers, antimicrobials, moisture absorbers, and ethylene scavengers. We present methods of incorporation of metal-organic frameworks into packaging materials and their applications.
\end{abstract}

Keywords Metal-organic frameworks $\cdot$ Food packaging $\cdot$ Food safety $\cdot$ Scavenger $\cdot$ Absorber $\cdot$ Antimicrobial

\section{Introduction}

Around one-third of the food produced for human consumption is lost or wasted, and it has been reported that $59-65 \%$ of the food waste can be avoided (Gupta et al. 2021a; Kumar et al. 2021c; Blanke, 2014). Broadly, food can be categorized into plant-based food such as fruits and vegetables, cereal-based products, and animal-based food such as meatbased products. Food undergoes spoilage due to microbial contamination, enzymatic degradation, oxidation, excess of ethylene, uncontrolled temperature, undesirable moisture, and inadequate $\mathrm{pH}$. Several techniques are implemented to avoid food spoilage, maintain quality and prevent wastage throughout the supply chain (Kumar et al. 2021a; de Souza et al. 2018; Gupta et al. 2021b). But currently used techniques are not effective enough and have an adverse effect

Ajay Kathuria

akathuri@ calpoly.edu

$\triangle$ Kirtiraj K. Gaikwad

kirtiraj.gaikwad@pt.iitr.ac.in

1 Department of Paper Technology, Indian Institute of Technology Roorkee, Roorkee, Uttarakhand 247667, India

2 Industrial of Technology and Packaging, California Polytechnic State University, San Luis Obispo, CA 93407, USA on the environment (Gupta et al. 2021b; Pandiselvam et al. 2019). One of the potential ways is improving the packaging attributes to reduce the undesirable changes in the food (Singh et al. 2021b; Kumar et al. 2021a). Food packaging plays a critical role in food supply chain and preserving the quality of food (Kumar et al. 2021b). Evolution in food packaging research has led to the exploration of innovative active packaging developed by incorporation of bioactive components, antimicrobial peptides, metal-organic frameworks (MOFs), and many more to achieve desired active packaging (Jafarzadeh et al. 2020; Sultana et al. 2021; Sharanyakanth and Radhakrishnan 2020). The paper aims to summarize the application of metal-organic frameworks in the food packaging sector.

Metal-organic frameworks are an extensive class of hybrid organic-inorganic supramolecules composed of metals ions linked via organic bridge ligands forming a crystalline-porous structure (Rocío-Bautista et al. 2019). Metal-organic frameworks possess a higher specific surface area than traditional porous material (Farah et al. 2012). Dynamic interactions, size, and selectivity between pores and target guest molecules can be regulated via organic and inorganic building blocks (Deng et al. 2010; Gücüyene et al. 2010). Commonly used metal ions for the fabrication of chemically stable metal-organic frameworks are aluminum, iron, zirconium, titanium, copper, and zinc (Yuan et al. 2018; Low et al. 2009; Neves et al. 2021). 
Earlier, hydrothermal and solvothermal methods were used to synthesize metal-organic frameworks, but they had a drawback of long processing time. This led to the development of advanced techniques such as mechanochemical, microwave-assisted, sonochemical, electrochemical methods. Solvothermal or hydrothermal methods involve conventional electric heating in nuclear magnetic resonance tubes or vials (Lee et al. 2013). In the microwave-assisted method, the Teflon vessel is loaded with substrate components and solvent. It is then sealed and exposed to microwave radiation to generate a specific controlled temperature and a particular time. In this method, the oscillating electric field is combined with the permanent dipole moment of the molecules present in the solvent medium, causing heating (Kerner et al. 2001; Xu et al. 2006). The porous chromium trimesate (MIL-100) was the first known metal-organic framework synthesized via the microwave-assisted method (Jhung et al. 2005). In sonochemical synthesis, the solution is loaded into the horn-type Pyrex reactor attached with a sonicator bar. Sonication promotes the formation and collapsing of the bubble (known as acoustic cavitation) resulting from high pressure and temperature, ultimately leading to the fabrication of fine crystals (Stock and Biswas, 2011). In electrochemical synthesis, anodic dissolution is used as a metal ion producer which reacts with the dissolved linkers and salts present in the medium. Deposition on the cathode can be prevented by using protic solvents, but it produces hydrogen as a by-product (Mueller et al. 2006). In mechanochemical synthesis, intramolecular bonds are broken mechanically following chemical transformation (Stock and Biswas, 2011). Figure 1 represents the diagrammatic illustration of types of synthesis method of metal-organic frameworks.

Metal-organic frameworks act as adsorbents and catalysts for air purification due to their ability to remove particulate matter from the air (Decoste and Peterson 2014; Barea et al. 2014; Wang et al. 2018; Zhang et al. 2016; Chen et al. 2017). Removal of free fatty acids and peroxy compounds can be performed via cobalt, iron, and zinc-based metal-organic frameworks (Vlasova et al. 2018). Metal-organic frameworks have scope in the development of hydrogen peroxide detection sensors. In the food industry, hydrogen peroxide is widely used for sterilization of equipment and also for preservation. But exceeding the permissible limit (35\% (w/w) in food package) may lead to serious health issues. This issue has encouraged the development of the iron oxide-based metal-organic framework sensor. Metal-organic frameworks can be used as a sensor; for instance, luminescent metal-organic frameworks can be used as fluorescent sensors for effective monitoring and to decrease the food safety monitoring problems (Du et al. 2021). Similarly, many other

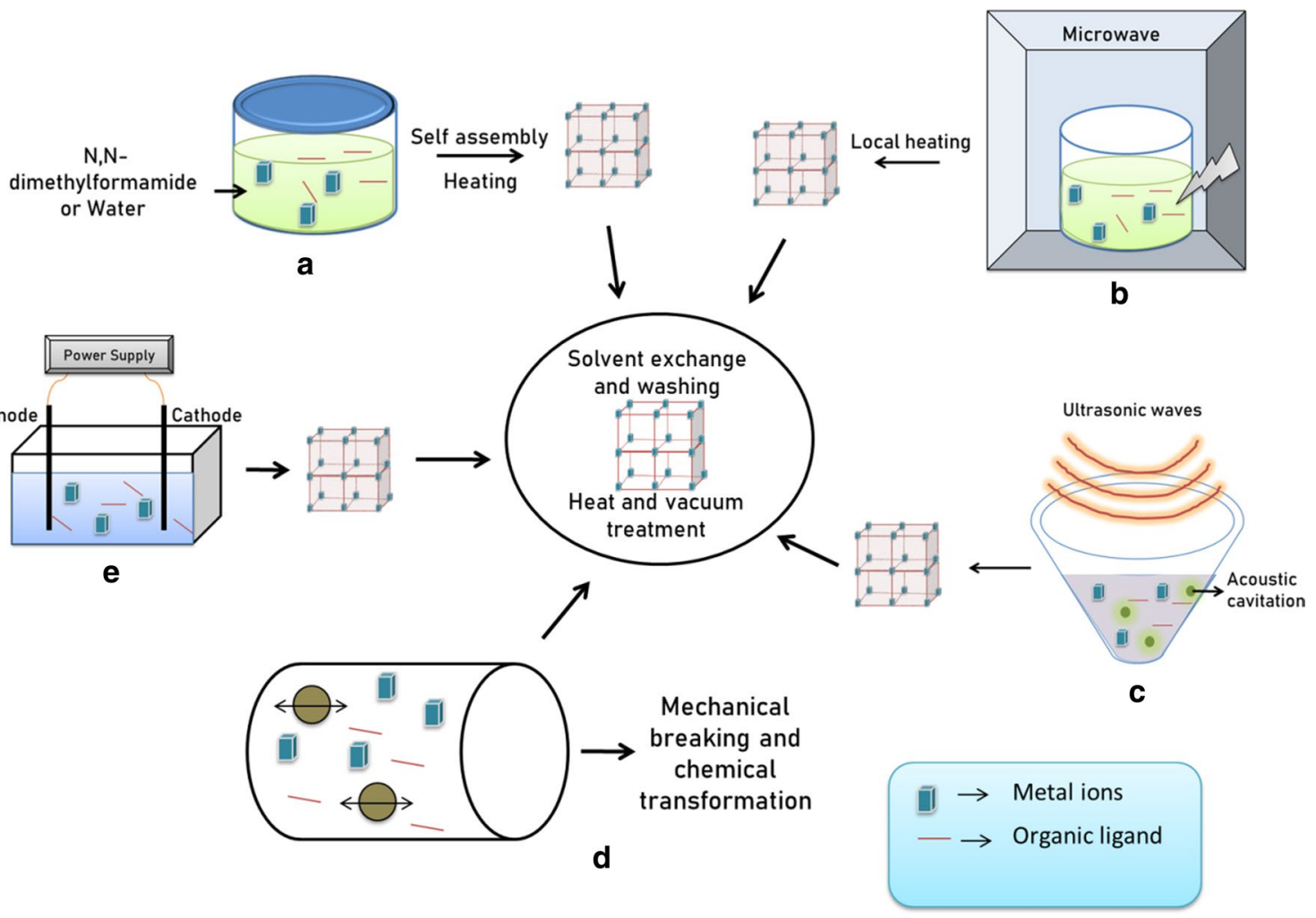

Fig. 1 Common methods for synthesis of metal-organic frameworks: a hydrothermal or solvothermal synthesis, $\mathbf{b}$ microwave-assisted synthesis, c sonochemical synthesis, $\mathbf{d}$ mechanochemical synthesis, and e electrochemical synthesis 
electrochemical and fluorescence metal-organic frameworks have been studied to determine chemical quality and food safety (Liu and Yin 2016). In an investigation, cellulosebased material was incorporated with MIL-125(Ti)- $\mathrm{NH}_{2}$ (nano-metal-organic frameworks). It was observed that the mechanical performance, including tensile strength and elongation at break of the film, improved by $6.5 \sim 25.9 \%$, and a slight increment in contact angle from $60.6^{\circ}$ and $60.9^{\circ}$ was also recorded. Hence, it has been concluded that the incorporation of nano-metal-organic frameworks in cellulose film can be used for the development of multifunctional film, which has application in the packaging of food (Sun et al. 2021).

The focus of this review paper is limited to the various potential roles of metal-organic frameworks in food packaging. It also highlights the challenges which need to be overcome to obtain a food packaging incorporated or made up of metal-organic frameworks with desired attributes. Moreover, efforts are being made to implement techniques such as surface modification to design metal-organic frameworks as an effective active agent.

\section{Metal-organic frameworks}

Widely used active agents such as zeolite have been studied seen for several years but have certain shortcomings, including high operational cost and low thermal stability (Kathuria et al. 2021; Ghazvini et al. 2021). This led to the study of metal-organic frameworks to overcome such shortcomings and improve efficiency. Metal-organic frameworks can be classified based on the structural framework, synthesis stage, the crystal structure arrangement, and stimuli (Singh et al. 2018). Based on the structural framework, metal-organic frameworks are divided into (i) flexible metal-organic frameworks: in the presence of external stimuli, reversible change of structural conformation is possible and (ii) rigid metal-organic frameworks: structural confirmation is not possible in the presence of external stimuli. Based on synthesis stages, metal-organic frameworks are categorized into three generations: (i) first-generation metal-organic frameworks: metal-organic frameworks having basic structure consisting of an organic and inorganic moiety, (ii) second-generation metal-organic frameworks: metal-organic frameworks which undergo post-synthesis surface modification, and (iii) third generation metal-organic frameworks: metal-organic frameworks which consist of biomolecules within the framework. Based on crystal structure arrangement, metal-organic frameworks are of two types: (i) crystalline: metal-organic frameworks which have an infinite arrangement of the regular solid framework and (ii) amorphous: metal-organic frameworks, which consists of a highly disordered framework. Based on stimuli, it is classified into single stimuli: triggered by single stimulus and multi-stimuli: triggered by more than one stimuli (Cheetham et al. 2006; Perry et al. 2009; Farha et al. 2010; Bennett et al. 2014). Figure 2 represents the classification of metal-organic frameworks.

\section{Metal-organic frameworks for active packaging}

Active packaging is a packaging system that involves the incorporation of active agents into the packaging material to enhance the safety, quality, and shelf life of the food (Kumar et al. 2021c; Vilela et al. 2018). Active packaging preserves food as it comprises functional systems such as releasing system, absorbing system, removing system, temperature control, microbial control, and quality control (Restuccia et al. 2010; Yildirim et al. 2018). Methods of fabricating such systems include surface modification, coating, immobilizing,

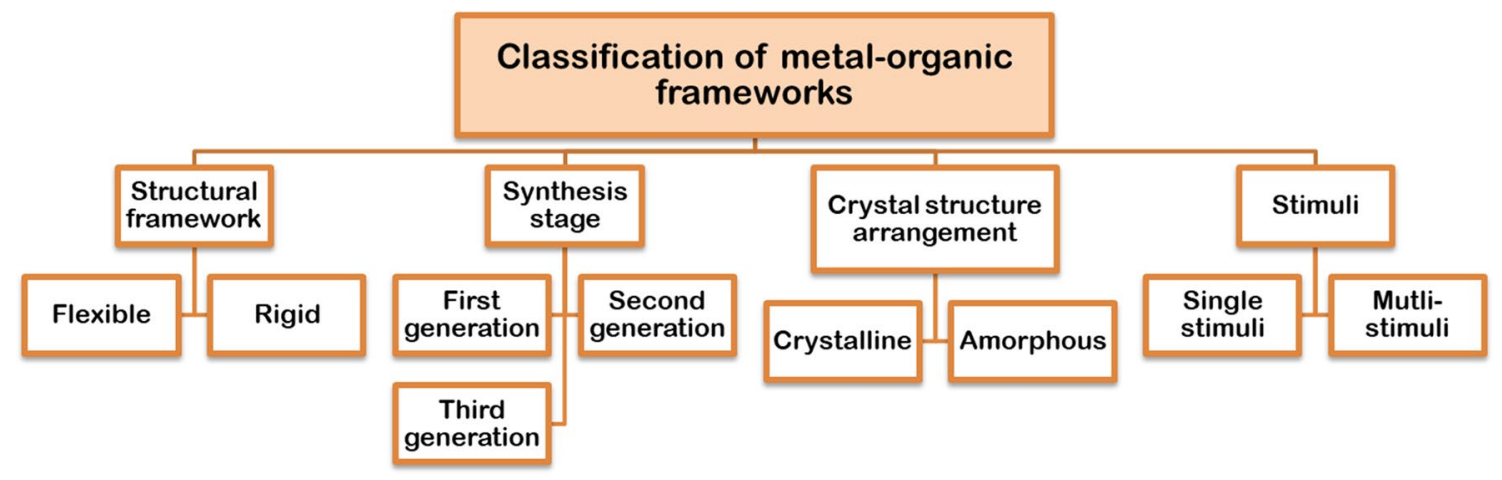

Fig. 2 Classification of metal-organic frameworks based on the structural framework, synthesis stage, the crystal structure arrangement, and stimuli. Based on the structural framework, it is further classified into flexible and rigid, based on the synthesis stage, it is classified as the first stage, second stage, and third stage generation, based on an arrangement of the crystal structure, it can be divided into crystalline and amorphous and based on stimuli it can be grouped as single stimuli and multi-stimuli 
or incorporating active agents onto the packaging material (Bastarrachea et al. 2015). Active agents can be natural or synthetic, but due to consumer demand and considering the environmental impact of the packaging material, the focus is shifted toward biodegradable and edible packaging material (Valdés et al. 2014, 2015; Silva-Weiss et al. 2013). Recent studies have shown that metal-organic frameworks are one of the potential active agents as it possesses oxygen scavenging, antimicrobial, moisture absorbing, and ethylene scavenging activity. Metal-organic frameworks can also serve as host molecules for controlled release of active organic molecules such as 1-Methyl Cyclopropene (1-MCP), hexanal, ethanol among others. Such host-guest systems can be deployed for active packaging applications.

\section{Metal-organic frameworks as oxygen scavenger or absorber}

The presence of oxygen in the package headspace leads to oxidative reactions in food, which is one of the causes of spoilage (Gaikwad et al. 2018; Singh et al. 2021a). Removal of hazardous or undesirable gas molecules can be efficiently performed via selective gas adsorption (Singh et al. 2019). Currently, porous materials such as zeolite, activated carbon, and silica are considered for gas adsorption, which works on the principle of the pressure difference between the outside and inside of the adsorbent (Davis 2002; Dąbrowski 2001; Bein et al. 2005). But demand is arising for eco-friendly, cost-effective, energy-saving, and improved efficiency (Gaikwad et al. 2020b; He and Li, 2017). Metal-organic frameworks possess high surface area, microporous nature (diameter $<2 \mathrm{~nm}$ ) and high pore volume, ultrahigh porosity, and about $90 \%$ of the empty space, which makes them potential candidates as a gas absorber (Férey 2008; Janiak et al. 2010; Yaghi et al. 2003; Li et al. 2009; Kitagawa et al. 2004). Hence, metal-organic frameworks play a key role in designing an active packaging system for scavenging oxygen to enhance food shelf life (He et al. 2015). Metal-organic frameworks can be flexibly designed as per the requirement due to their well-organized structure and thermal stability (Pang et al. 2012; Cavka et al. 2008; Sindoro et al. 2013). Metal-organic frameworks are usually found in powder form, but the crystalline structure is preferable for gas adsorption. In a study, covalent organic framework was loaded with dopamine which was further incorporated into the polylactic acid matrix, and the radical scavenging study suggests the antioxidant activity of the bio-nanocomposite (García et al. 2020). The three ways by which metal-organic frameworks selectively adsorbs gas are adsorbent-adsorbate interaction, molecular sieving effect, and stimuli-responsive gate-opening process ( $\mathrm{He}$ et al. 2016). Figure 3 shows the schematic representation of metal-organic frameworks as oxygen absorbers via three pathways.

\section{Adsorbent-adsorbate interaction}

Adsorbent-adsorbate interaction involves the affinity of the interaction between metal-organic frameworks internal surface and adsorbent; such interaction can occur due to Van der Waals forces of interaction such as hydrogen bonding, polarity, and quadruple moment (He et al. 2016). Metal-organic frameworks can possess diverse adsorption sites with varying binding energy depending on the charges and electron cloud distribution (Ghazvini et al. 2021). In an investigation, rht-type metal-organic framework PCN-61 (consists of 5,5',5"-benzene1,3,5-triyltris(1-ethynyl-2-isophthalate) linker), was capable of absorbing hydrogen molecules more effectively attributed to strong charge-quadrupole interactions (Forrest et al. 2012).

\section{Molecular sieving effect}

The molecular sieving effect is selective adsorption of the specific gas molecule by metal-organic frameworks depending on pore or channel size. Metal-organic frameworks consist of minute pores and gas molecules smaller than the pore size can fit into it, resulting in selective gas adsorption. For instance, a study reported that MUF-16 (MUF = Massey University Framework) was capable of selectively adsorbing carbon dioxide over methane, acetylene, ethylene, ethane, propylene, and propane (Qazvini et al. 2021). Similarly, another study shows selective nitrogen adsorption via Vanadium (II) metal-organic framework from the mixture consisting of ethylene (Jaramillo et al. 2020). Li and colleagues have reported the selective absorption of oxygen and carbon dioxide over nitrogen by tetrazolate-based ligand, 2,3-di-1H-tetrazol-5-ylpyrazine having a diameter of $4.1 \AA$ (Li et al. 2008).

\section{Stimuli-responsive gate-opening process}

In the stimuli-responsive gate-opening process, gas molecules enter into the pores of metal-organic framework structure when triggered by environmental factors such as temperature (Maji et al. 2004; Ghosh et al. 2008), pressure (Kitaura et al. 2004), and light irradiation (Luo et al. 2014; Lyndon et al. 2013; Heinke et al. 2014) through gate opening. In a study, diarylethene-azobenzene metal-organic framework showed distinct adsorption of different guest molecules due to the photosensitive attribute of metal-organic framework. Radial distribution function interpreted that the center of metal-organic framework is $-\mathrm{N}=\mathrm{N}$ - photosensitive and thus, has a higher adsorption affinity toward carbon dioxide (3.4 $\AA$ ) over ethane $(4.3 \AA)$ and methane (4.9 $\AA$ ) (Fan et al. 2017). Temperature triggered selective gas absorption was investigated for $\mathrm{Cu}(\mathrm{FMA})$ $(4,40-\mathrm{Bpe})_{0: 5}[\mathrm{FMA}=$ fumarate$; \mathrm{Bpe}=$ trans-bis $(4-$ pyridyl $)$ 


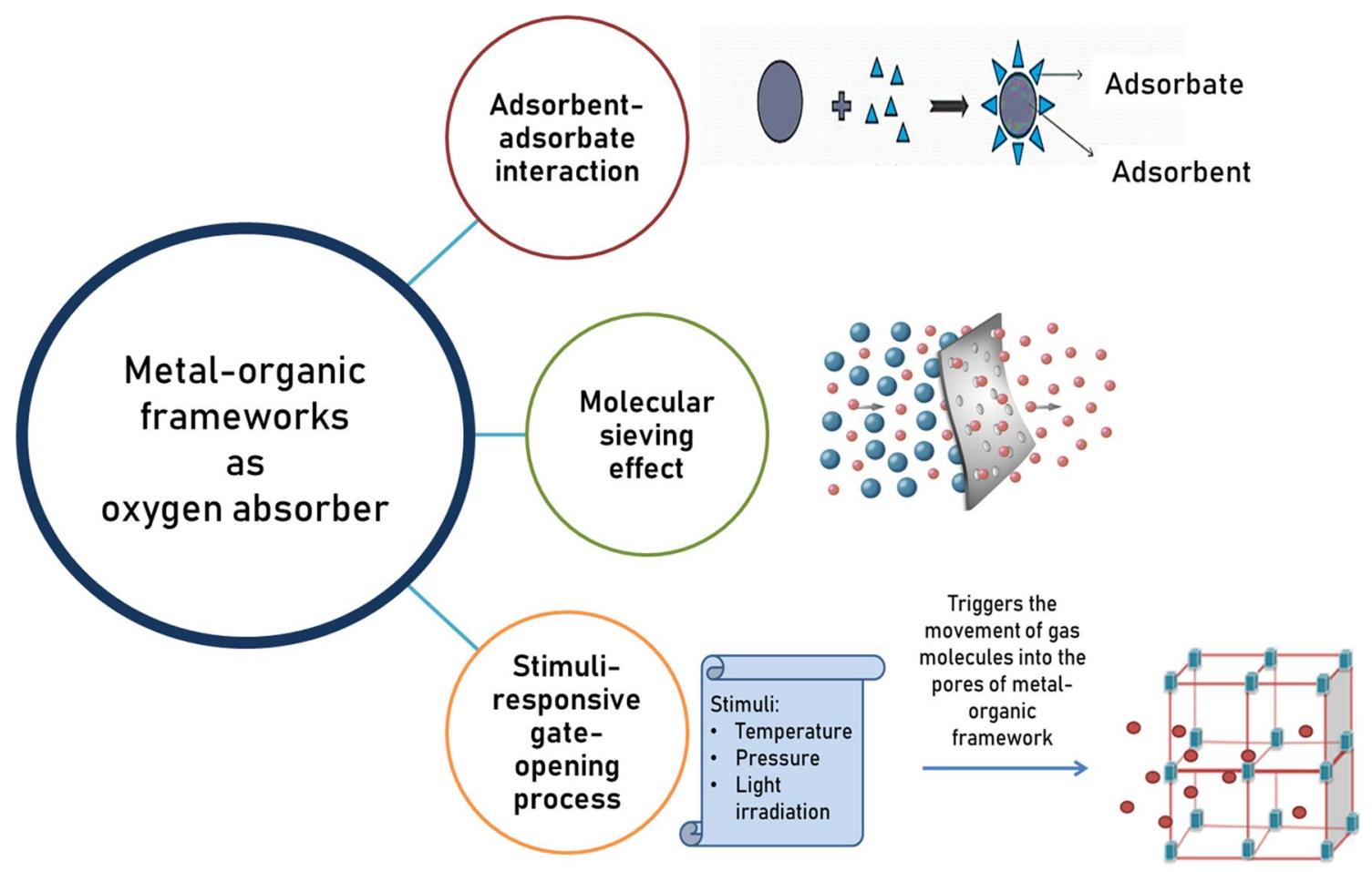

Fig. 3 Mechanisms of oxygen absorption by metal-organic frameworks: adsorbent-adsorbate interaction, molecular sieving, and stimuli-responsive gate-opening process. Adsorbent-adsorbate interaction is the interaction between internal surface of the metal-organic framework and adsorbate, molecular sieving effect involves the selective adsorption based on pore size, and stimuli-responsive gateopening process involves the entry of gas molecule when triggered by environmental factors ethylene] metal-organic frameworks. It was observed that at $77 \mathrm{~K}$ temperature, metal-organic frameworks are capable of adsorbing $91.8 \mathrm{~cm}^{3} \mathrm{~g}^{-1}$ of hydrogen over argon, carbon monoxide, and nitrogen. And on increasing the temperature to $195 \mathrm{~K}$, carbon dioxide adsorption over methane was observed (Chen et al. 2007).

\section{Metal-organic frameworks as antimicrobial agent}

The antimicrobial activity of active agents depends on the structure and composition of the agent as well the cell wall of the bacteria (Singh et al. 2021d; Gaikwad et al. 2019b; Mba and Nweze, 2021; Willdigg and Helmann 2021). Studies have shown that bacteria with a thick peptidoglycan layer (i.e., gram-positive bacteria) find it difficult to penetrate through the metal-organic frameworks surface. In the case of gram-negative bacteria (i.e., bacteria with thin peptidoglycan layer), higher sensitivity is observed, and thus, low minimum inhibition concentration is capable of achieving a large zone of inhibition (Karimi et al. 2020; Rojas et al. 2019; Wyszogrodzka et al. 2016; Nong et al. 2021; Shen et al. 2020). Biocidal activity of metal-organic frameworks may occur because of the release of metal ions which disrupts bacterial cell membrane integrity and/or due to the active site on the surface of metal-organic frameworks, which degrades protein and fatty acid present on the bacterial membrane. In some cases, the synergistic effect is observed when both metal ions and bioactive organic linkers participate in antimicrobial activity. Encapsulation of antimicrobial organic or inorganic guest molecules or ions in the metal-organic frameworks is another pathway to produce biocidal guest-host molecular systems (Berchel et al. 2011). In such systems, multiple molecular species or sites can participate in antimicrobial activity, such as metal ions, active linkers, and encapsulated guests (Kathuria et al. 2019; Pettinari et al. 2021). Figure 4 displays the schematic representation of metal-organic framework's antimicrobial activity mechanism.

Antibacterial activity of metal-organic frameworks consisting of silver, cobalt, zinc, copper, and other metal ions is widely studied and has proved potency against pathogenic microbes. The presence of light has shown a synergistic effect in improving biocidal activity. In a study, it was reported that bimetallic (Zinc and Cobalt) zeolitic imidazolate framework $\left(\mathrm{Zn}_{50} \mathrm{Co}_{50}\right.$-ZIF) improves antimicrobial activity by $45 \%$ in the presence of light (Ahmed et al. 2019). In another investigation, zinc-imidazolate framework- 8 (ZIF-8) metal-organic frameworks have shown more than 99.99\% inactivation efficiency against $E$. coli in the presence of solar irradiation for two hours under conditions ( $\mathrm{Li}$ 


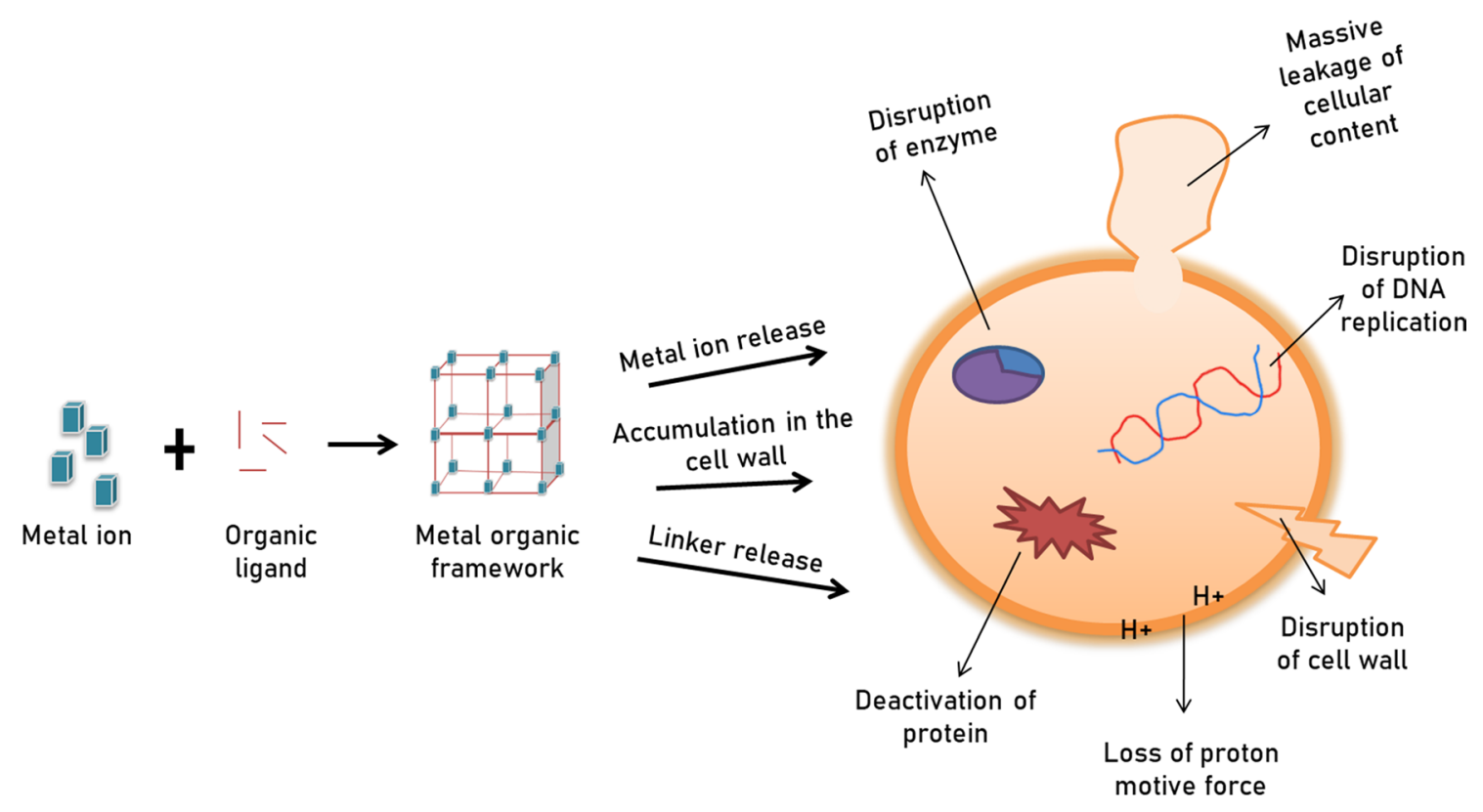

Fig. 4 Mechanism enabling the antimicrobial property of metalorganic frameworks. The three main pathways are metal ion release, accumulation in the cell wall, and linker release. These pathways may

et al. 2019). In research, silver nanoparticles were dispersed into the HKUST-1, which was further deposited on carboxymethylated fibers (Silver nanoparticles@ HKUST-1@ carboxymethylated fibers) to form a composite. Antibacterial analysis showed that (Silver nanoparticles@ HKUST1 @ carboxymethylated fibers) samples were capable of reducing surviving Staphylococcus aureus colonies from 170 to 1 (Duan et al. 2018). Viruses such as coronavirus, human immunodeficiency virus, and the Ebola virus have increased the concern for the development of potential antiviral agents. One of the challenges is early-stage detection to avoid spreading and as well as to implement properly on-time treatment. Some recent studies have shown the use of metal-organic frameworks for designing diagnosis techniques (Wang et al. 2020; Figueira et al. 2021). Some of the antimicrobial metal-organic frameworks are mentioned in Table 1.

\section{Metal-organic frameworks as moisture absorber}

Even though moisture in food products is useful for the quality of foods, excess moisture in a package is unfavorable to the quality of the food product and the integrity of the package, particularly in the case of high water activity food such as fresh produce and raw meat. In those cases, including moisture absorbers in food packages is helpful (Gaikwad et al. 2019c). The common process involved in moisture absorption in food packages is physical adsorption. Here, the moisture absorption capacity is reviewed with respect lead to disruption of the enzyme, massive leakage of cellular content, disruption of DNA replication, cell wall disruption, loss of proton motive force, and deactivate protein

to packages containing high water activity food. Due to microporous nature, various moisture stable metal-organic frameworks can absorb moisture at relative humidity such as $10 \%$ relative humidity (Xu and Yaghi 2020). In addition, metal-organic frameworks can be geometrically and chemically modified to obtain desired attributes for water absorption and water harvesting application (Llewellyn et al. 2014; Kalmutzki et al. 2018; Rieth and Dincă 2017). The metal-organic frameworks water adsorption performance depends on three factors: (i) adsorption isotherm, (ii) mass transport water, and (iii) energy transport (Liu et al. 2020). Hydrolytic stability plays a critical role in designing metal-organic frameworks for water absorption ( $\mathrm{Li}$ et al. 2016).

The mechanism of water adsorption by metal-organic framework can occur via three pathways: chemisorption, physisorption, and capillary condensation. In chemisorption, water adsorption is due to chemical bonding in which enthalpy is high and chances of regeneration or reusage become low (Ramanayaka et al. 2019). Various metal-organic frameworks have partially saturated metal sites which are saturated by guest neutral donor ligands, and these ligands can be removed by heating under vacuum (Kalmutzki et al. 2018). Complete activation of metal-organic frameworks leads to removal of guest ligand and provides the open metal sites. The adsorption site of water may vary depending on the thermal ellipsoids. For instance, in a study, it was observed that in (Zn)MOF-74, at 24-100 ${ }^{\circ} \mathrm{C}$, the water molecule was removed from the center 
Table 1 Metal-organic frameworks possessing an antimicrobial activity

\begin{tabular}{|c|c|c|}
\hline Type of metal-organic frameworks & Antimicrobial activity & References \\
\hline$\left[\mathrm{Ag}_{2}(\mathrm{Cedcp})\right]_{\mathrm{n}}$ and $\left\{\left[\mathrm{Ag}_{4}(\mathrm{Cmdcp})_{2}\left(\mathrm{H}_{2} \mathrm{O}\right)_{4}\right] \cdot 4 \mathrm{H}_{2} \mathrm{O}\right\}_{\mathrm{n}}$ & $\begin{array}{l}\text { Rupturing of the bacterial cell membrane leads to cell } \\
\text { death. Propionibacterium acnes ATCC } 6919 \text { strain was } \\
\text { highly sensitive to }\left\{\left[\mathrm{Ag}_{4}(\mathrm{Cmdcp})_{2}\left(\mathrm{H}_{2} \mathrm{O}\right)_{4}\right] \cdot 4 \mathrm{H}_{2} \mathrm{O}\right\}_{\mathrm{n}} \text { and } \\
\text { Minimum inhibition concentration was recorded as } \\
2.51 \mu \mathrm{M}\end{array}$ & Xie et al. (2020) \\
\hline$\left[\mathrm{Ag}_{2}(\mathrm{O}-\mathrm{IPA})\left(\mathrm{H}_{2} \mathrm{O}\right) \cdot\left(\mathrm{H}_{3} \mathrm{O}\right)\right]$ and $\left[\mathrm{Ag}_{5}(\mathrm{PYDC})_{2}(\mathrm{OH})\right]$ & $\begin{array}{l}\text { For }\left[\mathrm{Ag}_{2}(\mathrm{O}-\mathrm{IPA})\left(\mathrm{H}_{2} \mathrm{O}\right) \cdot\left(\mathrm{H}_{3} \mathrm{O}\right)\right] \text {, the diameter of zone of } \\
\text { inhibition against Escherichia coli and Staphylococcus } \\
\text { aureus was recorded as } 20 \mathrm{~mm} \text { and } 16 \mathrm{~mm} \text {, respectively. } \\
\text { And for }\left[\mathrm{Ag}_{5}(\mathrm{PYDC})_{2}(\mathrm{OH})\right] \\
\text { it was observed as } 17 \mathrm{~mm} \text { and } 14 \mathrm{~mm} \text { for Escherichia coli } \\
\text { and Staphylococcus aureus, respectively }\end{array}$ & Lu et al. (2014) \\
\hline $\left.\mathrm{Ag}_{2}(\mathrm{O}-\mathrm{IPA})\left(\mathrm{H}_{2} \mathrm{O}\right)\right]\left(\mathrm{H}_{3} \mathrm{O}\right)$ & $\begin{array}{l}\text { Minimum inhibition concentration for Escherichia coli } \\
\text { was recorded as } 5 \mathrm{ppm} \text {, and the largest diameter of zone } \\
\text { of inhibition was } 11.12 \mathrm{~mm}\end{array}$ & Chu et al. (2020) \\
\hline$[\mathrm{AgL}]_{\mathrm{n}} \cdot \mathrm{nH}_{2} \mathrm{O}$ & $\begin{array}{l}\text { Sustained release and better antibacterial property against } \\
\text { Fusobacterium nucleatum (ATCC 10,953, Fn), Strepto- } \\
\text { coccus mutans (UA159), and Porphyromonas gingivalis } \\
\text { (ATCC } 33,277, \mathrm{Pg} \text { ) compared to } \mathrm{AgNO}_{3} \text { was observed } \\
\text { by }[\mathrm{AgL}]_{\mathrm{n}} \cdot \mathrm{nH}_{2} \mathrm{O}\end{array}$ & Cao et al. (2020) \\
\hline $\begin{array}{l}\text { Ag-2-methylimidazole, Ag-imidazole, and Ag-benzimi- } \\
\text { dazole }\end{array}$ & $\begin{array}{l}\text { In samples treated with Ag-2-methylimidazole, Ag- } \\
\text { imidazole, and Ag-benzimidazole, Escherichia coli } \\
\text { population reduced from } 96.2 \% \text { to } 10.3 \%, 16.4 \% \text {, and } \\
24.5 \% \text {, respectively. Viable Bacillus subtilis decreased } \\
\text { from } 97.3 \% \text { to } 16.1 \%, 19.5 \% \text {, and } 35.5 \% \text { in the presence } \\
\text { of Ag-2-methylimidazole, Ag-imidazole, and Ag-benzi- } \\
\text { midazole, respectively }\end{array}$ & Seyedpour et al. (2020) \\
\hline Co (CoSIM1), Zn (Zn-SIM1), and Ag (Ag-TAZ) & $\begin{array}{l}\text { Zone of inhibition for Anabaena species PCC } 7120 \text { and } \\
\text { Synechococcus species PCC } 7942 \text { by Co (CoSIM1), Zn } \\
\text { (Zn-SIM1), and Ag (Ag-TAZ) was observed as } 5 \mathrm{~mm} \\
\text { and } 3 \mathrm{~mm}, 2 \mathrm{~mm} \text { and } 1 \mathrm{~mm} \text {, and } 3 \mathrm{~mm} \text { and } 1 \mathrm{~mm} \text {, } \\
\text { respectively }\end{array}$ & Martin et al. (2017) \\
\hline 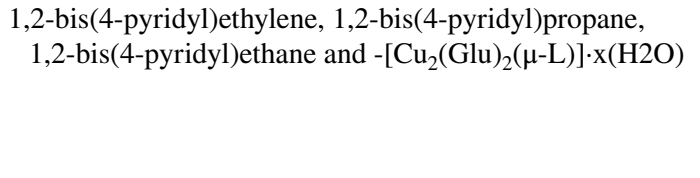 & $\begin{array}{l}\text { Minimum bactericidal concentration for Escherichia coli, } \\
\text { Pseudomonas aeruginosa, Staphylococcus aureus, Kleb- } \\
\text { siella pneumonia and Methicillin-resistant Staphylococ- } \\
\text { cus aureus by all the copper metal-organic framework } \\
\text { was less than } 20 \mu \mathrm{g} \mathrm{mL}^{-1}\end{array}$ & Jo et al. (2019) \\
\hline $\mathrm{Cu} / \mathrm{H}_{3} \mathrm{BTC}$ & $\begin{array}{l}\text { For Escherichia coli and Staphylococcus aureus zone of } \\
\text { inhibition was recorded as } 16 \mathrm{~mm} \text { and } 22 \mathrm{~mm} \text {, respec- } \\
\text { tively }\end{array}$ & Shams et al. (2020) \\
\hline $\mathrm{C}_{25} \mathrm{H}_{18} \mathrm{C}_{14} \mathrm{~F}_{8} \mathrm{FeN}_{12}$ and $\mathrm{C}_{24} \mathrm{H}_{16} \mathrm{C}_{12} \mathrm{~F}_{8} \mathrm{MnN}_{12}$ & $\begin{array}{l}\text { Least minimum inhibition concentration for } \\
\mathrm{C}_{25} \mathrm{H}_{18} \mathrm{C}_{14} \mathrm{~F}_{8} \mathrm{FeN}_{12} \text { against Escherichia coli, Staphylococ- } \\
\text { cus aureus and Pseudomonas fluorescence was recorded } \\
\text { as } 0.78 \mu \mathrm{g} \mathrm{mL}^{-1} \text {. And } \mathrm{C}_{24} \mathrm{H}_{16} \mathrm{C}_{12} \mathrm{~F}_{8} \mathrm{MnN}_{12} \text { showed mini- } \\
\text { mum inhibition concentration of } 0.78 \mu \mathrm{g} \mathrm{mL}^{-1} \text { against } \\
\text { Bacillus subtilis }\end{array}$ & Zhang et al. (2014) \\
\hline Iron trimesate & $\begin{array}{l}\text { Loading of Azidothymidine triphosphate (AZT-TP) into } \\
\text { metal-organic framework improved the antiviral activ- } \\
\text { ity by promoting the delivery of } 26 \% \text { of drugs into cell } \\
\text { within } 24 \text { h, while the pure form of AZT-TP shows less } \\
\text { than } 3 \% \text { of drug uptake }\end{array}$ & Agostoni et al. (2013) \\
\hline Zeolitic imidazolate framework loaded with rifampicin & $\begin{array}{l}\text { The inhibition rate of Escherichia coli and } S \text {. aureus was } \\
\text { more than } 80 \% \text { by the metal-organic framework }\end{array}$ & Song et al. (2018) \\
\hline
\end{tabular}

of the pore, and at $195{ }^{\circ} \mathrm{C}$, the water molecule chemisorbed is removed (Dietzel et al. 2008). Physisorption involves the adsorption of a water molecule on the primary adsorption site (near-polar hydrophilic centers), leading to water cluster formation (Furukawa et al. 2014). Capillary condensation is an irreversible process, which requires the pore diameter to be larger than the critical diameter, and it is calculated using the formula, 
Critical diameter $=\frac{4 \sigma T}{T-t}$

where $\mathrm{T}$ is critical temperature, $\mathrm{t}$ is adsorption temperature, and $\sigma$ is the van der Waals diameter of the adsorbate. It has been observed that the critical diameter of water is $20.76 \AA$ at $25{ }^{\circ} \mathrm{C}$ (Coudert et al. 2013; Abdulhalim et al. 2017; Kalmutzki et al. 2018). Figure 5 represents the diagrammatic illustration of three pathways of metal-organic frameworks as a moisture absorber.

In a study, four metal-organic frameworks were fabricated MOF-801-P, MOF-841, MOF-808, and UiO-66 with the pore volume of $0.45,0.53,0.84$, and $0.49 \mathrm{~cm}^{3} \mathrm{~g}^{-1}$, respectively, and the water capacity for MOF-801-P, MOF841, MOF-808, and UiO-66 was recorded as 450, 640, 735 and $535 \mathrm{~cm}^{3} \mathrm{~g}^{-1}$, respectively (Furukawa et al. 2014). In an investigation, $\mathrm{Cu}-\mathrm{MOF}$ nanoparticles were incorporated into cellulose acetate through a simple solution casting method. The incorporation of $7 \%$ of $\mathrm{Cu}-\mathrm{MOF}$ resulted in increasing the contact angle from $66.2^{\circ}$ to $78.1^{\circ}$, suggesting an improvement in hydrophobicity. Water vapor permeability results showed a decrease from $8.86 \times 10^{-7} \mathrm{~g} \cdot \mathrm{m}^{-1} \mathrm{~h}^{-1} \mathrm{~Pa}^{-1}$ to $5.82 \times 10^{-7} \mathrm{~g} \cdot \mathrm{m}^{-1} \mathrm{~h}^{-1} \mathrm{~Pa}^{-1}$ (Chen et al. 2021). In some studies, effect of functionalization of metal-organic frameworks is also observed to improve the desired quality of metal-organic frameworks. For instance, in an investigation,

\section{Chemisorption}

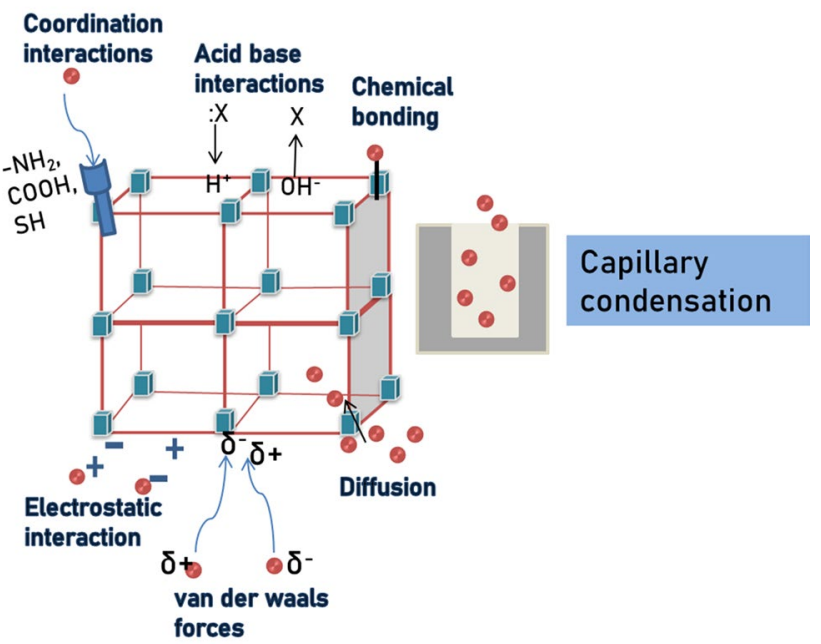

Physisorption

Fig. 5 Mechanisms of water adsorption by metal-organic frameworks: chemisorption (coordination interaction, acid-base interaction, and chemical bonding), physisorption (electrostatic interaction, van der Waals forces, and diffusion), and capillary condensation
UiO-67 was functionalized with $-\mathrm{NH}_{2}$ group, and the pore volume was recoded as 0.99 and 0.64 for $\mathrm{UiO}-67$ and $\mathrm{UiO}-$ 67-( $\left(\mathrm{NH}_{2}\right)_{2}$, respectively. Water uptake studies for UiO-67, at $\mathrm{P} / \mathrm{P}_{0}=0.1,0.3$ and 0.9 was recorded as 8,15 and $293 \mathrm{mg} \mathrm{g}^{-1}$, respectively. And for functionalized UiO-67-( $\left(\mathrm{NH}_{2}\right)_{2}$, water uptake was recorded as 30,173 and $262 \mathrm{mg} \mathrm{g}^{-1}$ at $\mathrm{P} / \mathrm{P}_{0}=0.1$, 0.3 and 0.9 , respectively (Ko et al. 2015). Hence, it can be observed that metal-organic frameworks have the potential as a moisture absorber due to their high surface area and crystalline structure.

\section{Metal-organic frameworks as ethylene scavenger}

Fruit ripening is one of the issues which leads to food spoilage and wastage. Shelf life and maturity of the fresh produce are impacted by the headspace concentration of ethylene phytohormone, generated by produce which accelerates ripening (Hu et al. 2019). An ethylene scavenging system is an active packaging system that promotes the preservation of fresh produce and prevents spoilage by extracting ethylene from the headspace of a package (Gaikwad et al. 2020c). The action of the mechanism of metal-organic frameworks for scavenging ethylene is not explicit; however, the available data suggests it is mainly due to electrostatic interaction between positively charged metal ions and p-electron of the ethylene molecule (Awalgaonkar et al. 2020).

In an investigation, two metal-organic frameworks, Basolite C300 (is copper-based and has trimesic acid linker group) and Basolite A520 (aluminum-based and has fumaric acid linker group), were studied for ethylene scavenging activity. The absorption study showed that $250 \mathrm{mg}$ of Basolite C300 could absorb $90 \%$ of ethylene while control (without absorber) and Basolite A520 absorbed only 22\%. It was also reported that the presence of carbon dioxide and nitrogen reduced ethylene absorption by around 30\% of Basolite $\mathrm{C} 300$. The highest desorption of ethylene was recorded for Basolite $\mathrm{C} 300$ as $7.8 \%$ within $4 \mathrm{~h}$. Thus, it was concluded that Basolite $\mathrm{C} 300$ could be used as a scavenger to prevent spoilage and releasing agent to aid ripening (Chopra et al. 2017). In an investigation, copper terephthalate metal-organic frameworks were prepared via a solvothermal mechanism. This metal-organic framework was placed inside a $4 \mathrm{~L}$ container consisting of banana and avocado and placed at $16{ }^{\circ} \mathrm{C}$. Results suggest that in $4 \mathrm{~L}$ of the container, $50 \mathrm{mg}$ of copper terephthalate metal-organic framework can absorb $654 \mu \mathrm{L} \mathrm{L}^{-1}$ of ethylene (Zhang et al. 2016). In a study, an alginate shell was incorporated with metal-organic framework comprising aluminum and trimethyl 1,3,5-benzenetricarboxylate ligands. The ethylene absorption capacity of the designed metal-organic framework was recorded as $41.0 \mathrm{~cm}^{3} \mathrm{~g}^{-1}$ metal-organic framework at $25{ }^{\circ} \mathrm{C}$ and $101.3 \mathrm{kPa}$. It was recorded that within three hours, $0.41-0.455 \mathrm{mg} \mathrm{L}^{-1}$ ethylene per $\mathrm{mg}$ 
aluminum metal-organic framework was released from the metal-organic framework matrix (Guan et al. 2019).

Metal-organic frameworks have their specific site for selective binding of ethylene and ethylene action inhibitor. For instance, a study observed that ethylene and 1-Methylcyclopropene efficiently bind to the copper site of HKUST-1 (Pnevskaya et al. 2021). However, studies have shown the potential of metal-organic frameworks as ethylene scavengers, but the dependence of its adsorption on relative humidity limits its usage (Awalgaonkar et al. 2020).

\section{Incorporation of metal-organic frameworks in packaging materials}

Metal-organic frameworks are highly ordered crystalline materials. The two main criteria for developing polymeric films consisting of metal-organic frameworks are selecting appropriate metal-organic framework as per the application and choosing the method to process it into a film. Metal-organic frameworks films can be classified as polycrystalline film and surface-mounted metal-organic frameworks (SURMOFs). Polycrystalline films are films with more or less randomly oriented metal-organic frameworks, and the thickness of the film depends on the size of metal-organic framework particles. SURMOF consists of perfectly oriented metal-organic frameworks with smooth surfaces, and the thickness of the film lies in nanometers (Betard et al. 2012).

The three ways to fabricate metal-organic framework active films include in situ interweaving, post-synthetic polymerization, and solvent-free hot-pressing. In situ interweaving involves electrochemical weaving of isolated metal-organic framework on the substrate using conducting polymers. Photoinduced post-synthetic polymerization consists of two steps; firstly, functional groups are used to modify organic ligand covalently, and then organic monomers are grafted on metal-organic frameworks via graft polymerization. The solvent-free hot-pressing method involves two stages; ligands or metal ions are chemically linked to the substrate with functional groups and metal sites on the surface. And then this leads to the growth of metal-organic framework crystals on the surface and nucleation (Ma et al. 2019). Self-assembled monolayers can be used as an interface for the incorporation of metal-organic framework for preparing the composite film, but it is not a practical method. Therefore, two techniques are employed: aged precursor solutions consisting of metal and ligands are used to immerse self-assembled monolayers, and the second is via liquid epitaxial layer-by-layer approach (Bradshaw et al. 2012). Liquid phase epitaxial is a method that involves layer-by-layer adsorption to the surface and alternative immersion of the substrate in positively charged solution and then in negatively charged solution (Decher 1997). Langmuir-Blodgett layer-by-layer deposition is a method that involves the transferring of metal-organic framework layers from one after another onto a substrate (silicon), including intermediate rinsing (Kitaura et al. 2003).

Hence, it can be stated that there are various methods for the fabrication of metal-organic framework films. However, there are still some challenges limiting its commercialization which can be overcome with advancements in technology. For instance, in a study, a metal-organic framework embedded film was prepared at room temperature within one-two hours with desired attributes via metal-hydroxidenanostrand-assisted confinement technique, in which solution of metal-hydroxide nanostrands was filtered, and the functional components are dispersed on porous matrix and further which is peeled off (Mao et al. 2014).

\section{Food packaging applications}

The incorporation of metal-organic frameworks into packaging materials is investigated in several studies to prevent food spoilage by absorbing moisture, preventing microbial deterioration, and delaying fruit ripening by controlling ethylene (Sharnayakanth et al. 2020). Active agent metal-organic frameworks can be incorporated into packaging in three ways: impregnation into packaging matrix, sachets, and coating (Fig. 6). Table 2 represents metal-organic frameworks in food packaging applications.

Kohsari and colleagues developed chitosan polyethylene oxide nanofibrous mats incorporated with zinc-imidazolate framework-8 nanoparticles. The antibacterial study revealed $100 \%$ inhibition of S. aureus and E.coli for chitosan polyethylene oxide nanofibrous mats consisting of $3 \%$ of zinc-imidazolate framework- 8 nanoparticles. The highest improvement in tensile strength $(22.78 \mathrm{MPa})$ was recorded by chitosan polyethylene oxide nanofibrous mats comprised of $10 \%$ of zinc-imidazolate framework- 8 nanoparticles (Kohsari et al. 2020). In another investigation, ferric iondoped hollow metal-organic frameworks were loaded with capsaicin and fabricated into gelatin and chitosan packaging film (Cap-Fe ${ }^{\mathrm{III}}$-HMOF-5). Apple cubes were coated with the designed coating and observed for five days, among which $8 \%$ of capsaicin showed no bacterial spoilage and minor oxidation on the fifth day of the experiment. Water vapor permeability of the film improved from 1.236 (control) to $1.794 \mathrm{~g}-10^{10}(\mathrm{~s} \cdot \mathrm{m} \cdot \mathrm{Pa})^{-1}\left(8 \% \mathrm{Cap}-\mathrm{Fe}^{\mathrm{III}}\right.$-HMOF-5) (Zhao et al. 2020). In a study, allyl isothiocyanate (natural antimicrobial compound) was incorporated into three metal-organic frameworks: HKUST-1, MOF-74(Zinc), and RPM6-Zinc. At a relative humidity of 30-35\%, metal-organic frameworks were able to retain the allyl isothiocyanate and released $70-96 \%$ at a high relative humidity of $95-100 \%$. This can 
Fig. 6 Incorporation of metalorganic frameworks into the packaging material to preserve food quality. It includes metal-organic frameworks impregnated packaging, sachets containing metal-organic framework, and coating of metal-organic framework

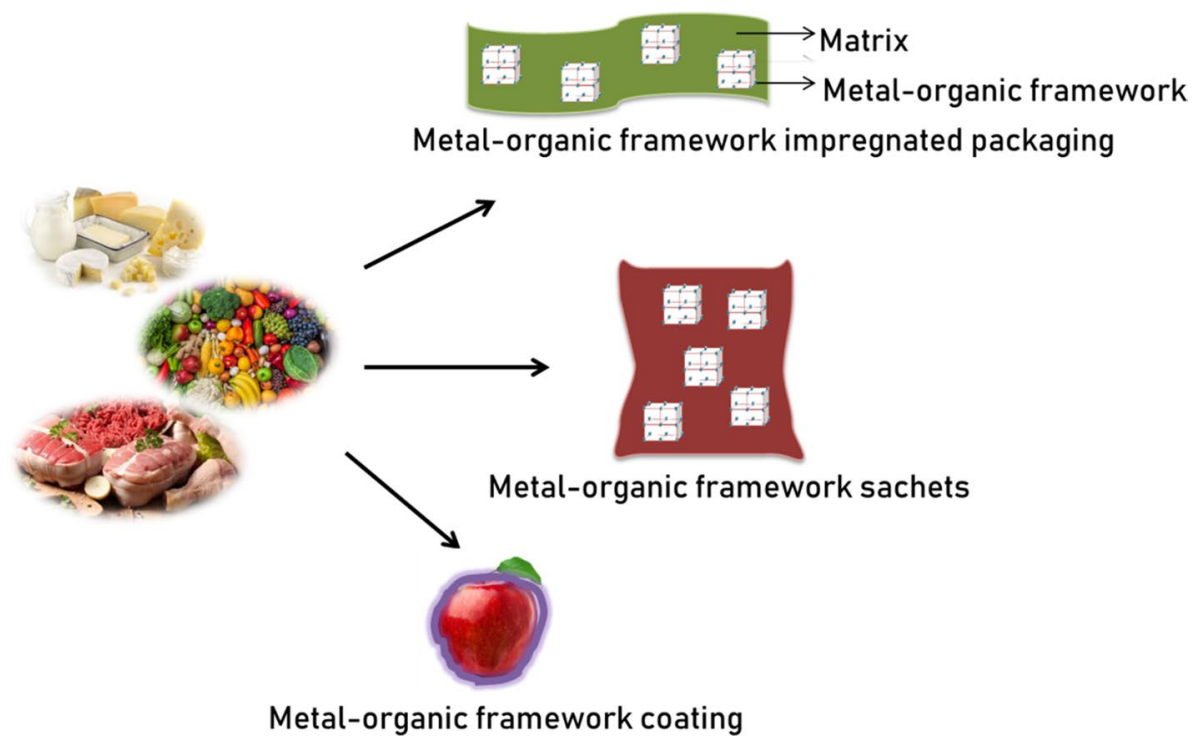

be used to develop food packaging to prevent microbial contamination (Lashkari et al. 2017). In an investigation, poly(L-lactic acid) was loaded with $15 \%$ zinc-imidazolate framework-8 metal-organic framework to develop active packaging film. As per the migration study, migration of zinc ions in low and high alcoholic stimulants was recorded as $166 \mathrm{mg} \mathrm{L}^{-1}$ and for aqueous and acidic food simulants as $354 \mathrm{mg} \mathrm{L}^{-1}$. Since the migration percentage was higher than acceptable, it cannot be considered for direct food contact (Kathuria et al. 2021).

Metal-organic frameworks can also be used to reduce the film's water vapor transmission rate; for instance, in a study, $\mathrm{Zr}_{6} \mathrm{O}_{4}(\mathrm{OH})_{4}$ (fumarate) $)_{6}$ was incorporated into cyclic olefin copolymer, and the water vapor transmissions rate study revealed a tenfold increase in the film containing metal-organic frameworks (Bae et al. 2016). Thus, researchers have reported the promising potential of metal-organic frameworks as an active agent to be impregnated into the packaging matrix to develop active, intelligent, smart materials for developing sustainable product-package systems for reducing food waste and greenhouse gas emissions.

\section{Perspective}

Metal-organic frameworks have vast applications potential because of their tailorability, diverse structural and compositional manipulation. However, several challenges exist which need to be addressed for their mass-scale food packaging applications. Some of them are mentioned below:

Although complications in the large-scale production of metal-organic frameworks (Kong and Li 2021) exist, researchers have reportedly produced metal-organic frameworks by extrusion processing (Casaban et al. 2021).
Separation of gas molecules having similarities in size is difficult via metal-organic frameworks (Hendon et al. 2017).

Fabrication of metal-organic frameworks is an expensive method (Julien et al. 2017). However, new fabrication methodologies such as extrusion have been reported, which indicates a promising future.

The capacity of metal-organic frameworks is low, which need to be modified (Vikrant et al. 2017).

Recycling of metal-organic frameworks is not an easy process (Kumar et al. 2019).

Toxicity of the metal-organic frameworks due to metal ions and organic ligands functional groups (Ouyang et al. 2018; Barea et al. 2014; Sajid, 2016; Jung et al. 2010).

Recycling and toxicity can be addressed by using naturally occurring biomolecules as ligands and environmentally benign transition metal or non-toxic metal ions such as alkali or alkaline earth metals.

Continuous scientific advances and understanding in the field of microporous and mesoporous materials have increased the possibility of commercial utilization of metal-organic frameworks in food packaging applications. Further modification or the tailored design of metal-organic frameworks can help in improving their functional performance. Such as, an efficient synthesis of metal-organic frameworks can be attained by reducing energy input, opting for safe and less costly building units, and implementing continuous processes (Kong and $\mathrm{Li}, 2021$ ). The reviewed literature suggests the applications of metal-organic frameworks in the packaging of fruits and vegetables during transportation and storage to scavenge ethylene which delays the ripening and maintains the freshness of the food. Metal-organic frameworks also have scope in the packaging of meat-based products to prevent lipid oxidation and microbial contaminations, which are the major cause of 


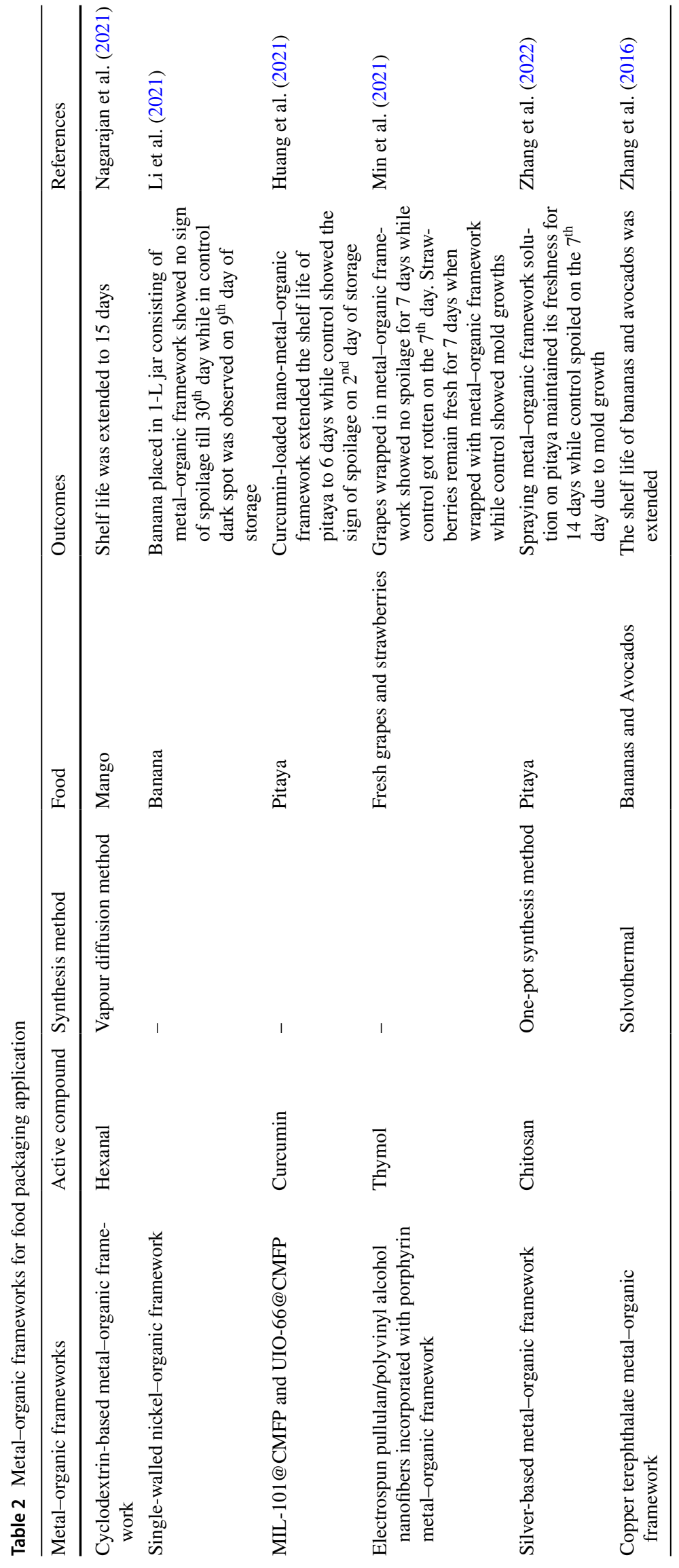


meat spoilage. Oxygen and moisture absorbing attributes of the packaging make it a good candidate for packaging crispy food products and maintaining the quality of food by preventing it from becoming soggy. Hence, food packaging involving metal-organic frameworks as an active agent has a promising potential to maintain food safety, quality and extend its shelf life.

\section{Conclusion}

To achieve food safety, it is necessary to detect, control, and remove the hazards and risks while the food reaches from the farm to the consumer's plate. Metal-organic frameworks act as potential agents due to their unique chemical and physical attributes. In this review, we have outlined various applications of metal-organic frameworks in food packaging. The role of metal-organic frameworks such as antimicrobial agent, antioxidant agent, oxygen scavenger, ethylene scavenger, and moisture absorber is discussed. The reviewed literature showed that the biocompatibility and nonreactive behavior of the metal-organic frameworks had increased the demand in the food packaging field. There are certain shortcomings such as high fabrication cost, recycling issue, low capacity, and inefficient separation of gas molecules, limiting the commercialization of metal-organic frameworks application in food packaging. Overcoming these challenges would help in the fabrication of efficient packaging material impregnated with metal-organic frameworks to maintain food safety, quality and extend its shelf life.

Acknowledgements Author K. K. Gaikwad would like to sincerely thank the Science and Engineering Research Board (SERB), Government of India, for the financial support provided under the Start-up Research Grant (SRG) (SRG/2021/001549) and author Ajay Kathuria is thankful for Orfalea funds for the release time.

Authors contribution The authors conceptualized the study design jointly. AS searched for and resolved conflicts, charted the data, and wrote the first draft. AK and KKG led the analysis and incorporated critical feedback from all authors.

\section{Declarations}

Conflict of interest The authors declare that they have no conflict of interest.

\section{References}

Abdulhalim RG, Bhatt PM, Belmabkhout Y, Shkurenko A, Adil K, Barbour LJ, Eddaoudi M (2017) A fine-tuned metal-organic framework for autonomous indoor moisture control. J Am Chem Soc 139:10715-10722. https://doi.org/10.1021/JACS.7B04132/ SUPPL_FILE/JA7B04132_SI_005.CIF
Agostoni V, Chalati T, Horcajada P, Willaime H, Anand R, Semiramoth N, Baati T, Hall S, Maurin G, Chacun H, Bouchemal K, Martineau C, Taulelle F, Couvreur P, Rogez-Kreuz C, Clayette P, Monti S, Serre C, Gref R (2013) Towards an improved antiHIV Activity of NRTI via metal-organic frameworks nanoparticles. Adv Healthc Mater 2:1630-1637. https://doi.org/10.1002/ ADHM.201200454

Awalgaonkar G, Beaudry R, Almenar E (2020) Ethylene-removing packaging: basis for development and latest advances. Compr Rev Food Sci Food Saf 19:3980-4007. https://doi.org/10.1111/ $1541-4337.12636$

Awalgaonkar GS (2018) Development of active packaging trays with ethylene removing capacity

Bae YJ, Cho ES, Qiu F, Sun DT, Williams TE, Urban JJ, Queen WL (2016) Transparent metal-organic framework/polymer mixed matrix membranes as water vapor barriers. ACS Appl Mater Interfaces 8:10098-10103. https://doi.org/10.1021/ACSAMI. 6B01299/SUPPL_FILE/AM6B01299_SI_001.PDF

Barea E, Montoro C, Navarro JAR (2014) Toxic gas removal - metalorganic frameworks for the capture and degradation of toxic gases and vapours. Chem Soc Rev 43:5419-5430. https://doi. org/10.1039/C3CS60475F

Bastarrachea LJ, Wong DE, Roman MJ, Lin Z, Goddard JM (2015) Active packaging coatings. Coatings. https://doi.org/10.3390/ COATINGS5040771

Bein T, Mintova S (2005) Advanced applications of zeolites. Stud Surf Sci Catal 157:263-288. https://doi.org/10.1016/S0167-2991(05) 80015-1

Bennett TD, Cheetham AK (2014) Amorphous metal-organic frameworks. Acc Chem Res 47:1555-1562. https://doi.org/10.1021/ $\operatorname{ar} 5000314$

Berchel M, Gall TL, Denis C, Hir SL, Quentel F, Elléouet C, Montier T, Rueff JM, Salaün JY, Haelters JP, Hix GB, Lehn P, Jaffrès PA (2011) A silver-based metal-organic framework material as a 'reservoir' of bactericidal metal ions. New J Chem 35:10001003. https://doi.org/10.1039/C1NJ20202B

Blanke MM (2014) Reducing ethylene levels along the food supply chain: a key to reducing food waste? J Sci Food Agric 94:23572361. https://doi.org/10.1002/JSFA.6660

Bradshaw D, Garai A, Huo J (2012) Metal-organic framework growth at functional interfaces: thin films and composites for diverse applications. Chem Soc Rev 41:2344-2381. https://doi.org/10. 1039/C1CS15276A

Cao P, Wu X, Zhang W, Zhao L, Sun W, Tang Z (2020) Killing oral bacteria using metal-organic frameworks. Ind Eng Chem Res 59:1559-1567. https://doi.org/10.1021/ACS.IECR.9B05659/ SUPPL_FILE/IE9B05659_SI_001.PDF

Casaban J, Zhang Y, Pacheco R, Coney C, Holmes C, Sutherland E, Hamill C, Breen J, James SL, Tufano D, Wong D, Stavrakakis E, Annath H, Moore A (2021) Towards MOFs' mass market adoption: MOF Technologies' efficient and versatile one-step extrusion of shaped MOFs directly from raw materials. Faraday Discuss 231:312-325. https://doi.org/10.1039/D1FD00025J

Cavka JH, Jakobsen S, Olsbye U, Guillou N, Lamberti C, Bordiga S, Lillerud KP (2008) A new zirconium inorganic building brick forming metal organic frameworks with exceptional stability. $\mathrm{J}$ Am Chem Soc 130:13850-13851. https://doi.org/10.1021/JA805 7953/SUPPL_FILE/JA8057953_SI_001.PDF

Cheetham AK, Rao CNR, Feller RK (2006) Structural diversity and chemical trends in hybrid inorganic-organic framework materials. Chem Commun. https://doi.org/10.1039/B610264F

Chen B, Ma S, Zapata F, Fronczek FR, Lobkovsky EB, Zhou HC (2007) Rationally designed micropores within a metal-organic framework for selective sorption of gas molecules. Inorg Chem 46:1233-1236. https://doi.org/10.1021/IC0616434/SUPPL_ FILE/IC0616434SI20061122_113149.CIF 
Chen Y, Zhang S, Cao S, Li S, Chen F, Yuan S, Xu C, Zhou J, Feng X, Ma X, Wang B (2017) Roll-to-roll production of metal-organic framework coatings for particulate matter removal. Adv Mater 29:1606221. https://doi.org/10.1002/ADMA.201606221

Chen K, Yu J, Huang J, Tang Q, Li H, Zou Z (2021) Improved mechanical, water vapor barrier and UV-shielding properties of cellulose acetate films with flower-like metal-organic framework nanoparticles. Int J Biol Macromol 167:1-9. https://doi.org/10.1016/J. IJBIOMAC.2020.11.164

Chopra S, Dhumal S, Abeli P, Beaudry R, Almenar E (2017) Metalorganic frameworks have utility in adsorption and release of ethylene and 1-methylcyclopropene in fresh produce packaging. Postharvest Biol Technol 130:48-55. https://doi.org/10.1016/J. POSTHARVBIO.2017.04.001

Chu HY, Fu H, Liu A, Wang P, Cao YL, Du AF, Wang CC (2020) Two silver-based coordination polymers constructed from organic carboxylate acids and 4, 4'-bipyridine-like bidentate ligands: synthesis, structure, and antimicrobial performances. Polyhedron 188:114684. https://doi.org/10.1016/J.POLY.2020.114684

Coudert FX, Boutin A, Fuchs AH, Neimark AV (2013) Adsorption deformation and structural transitions in metal-organic frameworks: from the unit cell to the crystal. J Phys Chem Lett 4:31983205. https://doi.org/10.1021/JZ4013849

Dạbrowski A (2001) Adsorption - from theory to practice. Adv Colloid Interface Sci 93:135-224. https://doi.org/10.1016/S00018686(00)00082-8

Davis ME (2002) Ordered porous materials for emerging applications. Nat. 4176891(417):813-821. https://doi.org/10.1038/ nature 00785

de Souza LP, Faroni LRDA, Heleno FF, Cecon PR, Gonçalves TDC, da Silva GJ, Prates LHF (2018) Effects of ozone treatment on postharvest carrot quality. LWT 90:53-60. https://doi.org/10. 1016/J.LWT.2017.11.057

Decher G (1997) Fuzzy nanoassemblies: toward layered polymeric multicomposites. Science 80:1232-1237

Decoste JB, Peterson GW (2014) Metal-organic frameworks for air purification of toxic chemicals. Chem Rev 114:5695-5727. https://doi.org/10.1021/CR4006473

Deng H, Doonan CJ, Furukawa H, Ferreira RB, Towne J, Knobler CB, Wang B, Yaghi OM (2010) Multiple functional groups of varying ratios in metal-organic frameworks. Science 327:846850. https://doi.org/10.1126/SCIENCE.1181761/SUPPL_FILE/ DENG.SOM.PDF

Dietzel PDC, Johnsen RE, Blom R, Fjellvåg H (2008) Structural changes and coordinatively unsaturated metal atoms on dehydration of honeycomb analogous microporous metal-organic frameworks. Chem Eur J. https://doi.org/10.1002/chem.200701370

Du T, Huang L, Wang J, Sun J, Zhang W, Wang J (2021) Luminescent metal-organic frameworks (LMOFs): an emerging sensing platform for food quality and safety control. Trends Food Sci Technol 111:716-730. https://doi.org/10.1016/J.TIFS.2021.03.013

Duan C, Meng J, Wang X, Meng X, Sun X, Xu Y, Zhao W, Ni Y (2018) Synthesis of novel cellulose- based antibacterial composites of Ag nanoparticles@ metal-organic frameworks@ carboxymethylated fibers. Carbohydr Polym 193:82-88. https://doi.org/10. 1016/J.CARBPOL.2018.03.089

Fan CB, Liu ZQ, Gong LL, Zheng AM, Zhang L, Yan CS, Wu HQ, Feng XF, Luo F (2017) Photoswitching adsorption selectivity in a diarylethene-azobenzene MOF. Chem Commun 53:763-766. https://doi.org/10.1039/C6CC08982H

Farah K, Müller-Plathe F, Böhm MC (2012) Classical reactive molecular dynamics implementations: state of the art. ChemPhysChem 13(5):1127-1151. https://doi.org/10.1002/cphc.201100681
Farha OK, Hupp JT (2010) Rational design, synthesis, purification, and activation of metal- organic framework materials. Accounts Chem Res. 43(8):1166-75

Farha OK, Eryazici I, Jeong NC, Hauser BG, Wilmer CE, Sarjeant AA, Snurr RQ, Nguyen ST, Yazaydin AÖ, Hupp JT (2012) Metalorganic framework materials with ultrahigh surface areas: is the sky the limit? J Am Chem Soc 134:15016-15021. https://doi. org/10.1021/JA3055639/SUPPL_FILE/JA3055639_SI_004.PDF

Férey G (2007) Hybrid porous solids: past, present, future. Chem Soc Rev 37:191-214. https://doi.org/10.1039/B618320B

Figueira F, Barbosa JS, Mendes RF, Braga SS, Paz FA (2021) Virus meet metal-organic frameworks: a nanoporous solution to a world-sized problem? Mater Today 43:84-98. https://doi.org/ 10.1016/J.MATTOD.2020.10.024

Forrest KA, Pham T, McLaughlin K, Belof JL, Stern AC, Zaworotko MJ, Space B (2012) Simulation of the mechanism of gas sorption in a metal-organic framework with open metal sites: molecular hydrogen in PCN-61. J Phys Chem C 116:15538-15549. https:// doi.org/10.1021/JP306084T/SUPPL_FILE/JP306084T_SI_002. ZIP

Furukawa H, Gándara F, Zhang YB, Jiang J, Queen WL, Hudson MR, Yaghi OM (2014) Water adsorption in porous metal-organic frameworks and related materials. J Am Chem Soc 136:43694381. https://doi.org/10.1021/JA500330A/SUPPL_FILE/JA500 330A_SI_010.PDF

Gaikwad KK, Singh S, Lee YS (2018) Oxygen scavenging films in food packaging. Environ Chem Lett 16(2):523-538. https://doi.org/10. 1007/s10311-018-0705-z

Gaikwad KK, Singh S, Lee YS (2019a) Antimicrobial and improved barrier properties of natural phenolic compound-coated polymeric films for active packaging applications. J Coat Technol Res 16(1):147-157

Gaikwad KK, Singh S, Ajji A (2019b) (2019c) Moisture absorbers for food packaging applications. Environ Chem Lett 17:609-628. https://doi.org/10.1007/s10311-018-0810-z

Gaikwad KK, Singh S, Negi YS (2020a) Ethylene scavengers for active packaging of fresh food produce. Environ Chem Lett 18(2):269284. https://doi.org/10.1007/s10311-019-00938-1

Gaikwad KK, Singh S, Negi YS, Lee YS (2020b) The effect of transpolyisoprene/LDPE based active films on oxidative stability in roasted peanuts. Food Measure 14(4):1857-1864. https://doi.org/ 10.1007/s11694-020-00433-0

Gaikwad KK, Singh S, Shin J, Lee YS (2020c) Novel polyisoprene based UV-activated oxygen scavenging films and their applications in packaging of beef jerky. LWT 117:108643. https://doi. org/10.1016/j.lwt.2019.108643

Ghazvini MF, Vahedi M, Nobar SN, Sabouri F (2021) Investigation of the MOF adsorbents and the gas adsorptive separation mechanisms. J Environ Chem Eng 9:104790. https://doi.org/10.1016/J. JECE.2020.104790

Ghosh SK, Bureekaew S, Kitagawa S, Ghosh SK, Bureekaew S, Kitagawa S (2008) A Dynamic, isocyanurate-functionalized porous coordination polymer. Angew Chemie 120:3451-3454. https:// doi.org/10.1002/ANGE.200705986

Guan Y, Teng Z, Mei L, Zhang J, Wang Q, Luo Y (2019) An entrapped metal-organic framework system for controlled release of ethylene. J Colloid Interface Sci 533:207-215. https://doi.org/10. 1016/J.JCIS.2018.08.057

Gücüyener C, Van Den Bergh J, Gascon J, Kapteijn F (2010) Ethane/ ethene separation turned on its head: Selective ethane adsorption on the metal-organic framework ZIF-7 through a gate-opening mechanism. J Am Chem Soc 132:17704-17706. https://doi.org/ 10.1021/JA1089765/SUPPL_FILE/JA1089765_SI_001.PDF

Gupta V, Ramakanth D, Verma C, Maji PK, Gaikwad KK (2021) Isolation and characterization of cellulose nanocrystals from amla 
(Phyllanthus emblica) pomace. Biomass Conv Bioref. https://doi. org/10.1007/s13399-021-01852-9

Gupta V, Yadav R, Tanwar R, Gaikwad KK (2021) к-Carrageenanbased bio-nanocomposite film reinforced with cellulose nanocrystals derived from amla pomace for food packaging. Biomass Conv Bioref. https://doi.org/10.1007/s13399-021-02028-1

He J, Li X (2017) Metal-organic framework for selective gas scavenging. J Mol Eng Mater. https://doi.org/10.1142/S22512373164001 4104,1640014

He J, Yap RCC, Wong SY, Li X (2015) Polymer composites for intelligent food packaging. J Mol Eng Mater 03:1540005. https://doi. org/10.1142/S2251237315400055

Heinke L, Cakici M, Dommaschk M, Grosjean S, Herges R, Bräse S, Wöll C (2014) Photoswitching in two-component surfacemounted metal-organic frameworks: optically triggered release from a molecular container. ACS nano. 8(2):1463-7

Hendon CH, Rieth AJ, Korzyński MD, Dincă M (2017) Grand challenges and future opportunities for metal-organic frameworks. ACS Cent Sci 3:554-563. https://doi.org/10.1021/ACSCE NTSCI.7B00197

Hu B, Sun DW, Pu H, Wei Q (2019) Recent advances in detecting and regulating ethylene concentrations for shelf-life extension and maturity control of fruit: a review. Trends Food Sci Technol 91:66-82. https://doi.org/10.1016/J.TIFS.2019.06.010

Huang G, Yan Y, Xu D, Wu J, Xu C, Fu L, Lin B (2021) Curcuminloaded nanoMOFs@CMFP: a biological preserving paste with antibacterial properties and long-acting, controllable release. Food Chem 337:127987. https://doi.org/10.1016/J.FOODCHEM. 2020.127987

Jafarzadeh S, Jafari SM, Salehabadi A, Nafchi AM, Uthaya Kumar US, Khalil HPSA (2020) Biodegradable green packaging with antimicrobial functions based on the bioactive compounds from tropical plants and their by-products. Trends Food Sci Technol 100:262-277. https://doi.org/10.1016/J.TIFS.2020.04.017

Janiak C, Vieth JK (2010) MOFs, MILs and more: concepts, properties and applications for porous coordination networks (PCNs). New J Chem 34:2366-2388. https://doi.org/10.1039/C0NJ00275E

Jaramillo DE, Reed DA, Jiang HZH, Oktawiec J, Mara MW, Forse AC, Lussier DJ, Murphy RA, Cunningham M, Colombo V, Shuh DK, Reimer JA, Long JR (2020) Selective nitrogen adsorption via backbonding in a metal-organic framework with exposed vanadium sites. Nat Mater 195(19):517-521. https://doi.org/10. 1038/s41563-019-0597-8

Jhung SH, Lee JH, Chang JS (2005) Microwave synthesis of a nanoporous hybrid material, chromium trimesate. Bulletin Korean Chem Soc 26(6):880-881. https://doi.org/10.5012/bkcs.2005.26.6.880

Jo JH, Kim HC, Huh S, Kim Y, Lee DN (2019) Antibacterial activities of $\mathrm{Cu}-\mathrm{MOF}$ containing glutarates and bipyridyl ligands. Dalt Trans 48:8084-8093. https://doi.org/10.1039/C9DT00791A

Julien PA, Mottillo C, Friščić T (2017) Metal-organic frameworks meet scalable and sustainable synthesis. Green Chem 19:27292747. https://doi.org/10.1039/C7GC01078H

Jung DW, Yang DA, Kim J, Kim J, Ahn WS (2010) Facile synthesis of MOF-177 by a sonochemical method using 1-methyl-2-pyrrolidinone as a solvent. Dalt Trans 39:2883-2887. https://doi.org/ 10.1039/B925088C

Kalmutzki MJ, Diercks CS, Yaghi OM, Kalmutzki MJ, Diercks CS, Yaghi OM (2018) Metal-organic frameworks for water harvesting from air. Adv Mater 30:1704304. https://doi.org/10.1002/ ADMA.201704304

Karimi H, Heidari MA, Emrooz HBM, Shokouhimehr M (2020) Carbonization temperature effects on adsorption performance of metal-organic framework derived nanoporous carbon for removal of methylene blue from wastewater; experimental and spectrometry study. Diamond Related Mater 108:07999. https:// doi.org/10.1016/j.diamond.2020.107999

Kathuria A, Pauwels AK, Buntinx M, Shin J, Harding T (2019) Inclusion of ethanol in a nano-porous, bio-based metal organic framework. J Incl Phenom Macrocycl Chem 95:91-98. https://doi.org/ 10.1007/S10847-019-00920-Y/FIGURES/7

Kathuria A, Harding T, Auras R, Kivy MB (2021) Encapsulation of hexanal in bio-based cyclodextrin metal organic framework for extended release. J Incl Phenom Macrocycl Chem 101:121-130. https://doi.org/10.1007/S10847-021-01095-1/FIGURES/8

Kerner R, Palchik O, Gedanken A (2001) Sonochemical and microwave-assisted preparations of $\mathrm{PbTe}$ and $\mathrm{PbSe}$. A Comparative Study Chem Mater 13:1413-1419. https://doi.org/10.1021/ CM001411H

Kitagawa S, Kitaura R, Noro SI (2004) Functional porous coordination polymers. Angew Chemie Int Ed 43:2334-2375. https://doi.org/ 10.1002/ANIE. 200300610

Kitaura R, Seki K, Akiyama G, Kitagawa S (2003) Porous coordination-polymer crystals with gated channels specific for supercritical gases. Angew Chemie Int Ed 42:428-431. https://doi.org/10. 1002/ANIE.200390130

Ko N, Hong J, Sung S, Cordova KE, Park HJ, Yang JK, Kim J (2015) A significant enhancement of water vapour uptake at low pressure by amine-functionalization of UiO-67. Dalt Trans 44:2047-2051. https://doi.org/10.1039/C4DT02582B

Kohsari I, Shariatinia Z, Pourmortazavi SM (2016) Antibacterial electrospun chitosan-polyethylene oxide nanocomposite mats containing ZIF-8 nanoparticles. Int J Biol Macromol 91:778-788. https://doi.org/10.1016/J.IJBIOMAC.2016.06.039

Kong X-J, Li J-R (2021) An overview of metal-organic frameworks for green chemical engineering. Engineering 7:1115-1139. https:// doi.org/10.1016/J.ENG.2021.07.001

Kumar P, Anand B, Tsang YF, Kim KH, Khullar S, Wang B (2019) Regeneration, degradation, and toxicity effect of MOFs: opportunities and challenges. Environ Res 176:108488. https://doi.org/ 10.1016/J.ENVRES.2019.05.019

Kumar L, Ramakanth D, Akhila K, Gaikwad KK (2021a) Edible films and coatings for food packaging applications: a review. Environ Chem Lett 2021(1):1-26. https://doi.org/10.1007/ S10311-021-01339-Z

Kumar A, Gupta V, Gaikwad KK (2021) Microfibrillated cellulose from pine cone: extraction, properties, and characterization. Biomass Conv Bioref. https://doi.org/10.1007/s13399-021-01794-2

Kumar A, Gupta V, Singh S, Saini S, Gaikwad KK (2021c) Pine needles lignocellulosic ethylene scavenging paper impregnated with nanozeolite for active packaging applications. Ind Crops Prod 170:113752. https://doi.org/10.1016/j.indcrop.2021.113752

Kumar Maji T, Uemura K, Chang H-C, Matsuda R, Kitagawa S, Maji TK, Uemura K, Chang H, Matsuda R, Kitagawa S (2004) Expanding and shrinking porous modulation based on pillaredlayer coordination polymers showing selective guest adsorption. Angew Chemie 116:3331-3334. https://doi.org/10.1002/ANGE. 200453923

Lashkari E, Wang H, Liu L, Li J, Yam K (2017) Innovative application of metal-organic frameworks for encapsulation and controlled release of allyl isothiocyanate. Food Chem 221:926-935. https:// doi.org/10.1016/J.FOODCHEM.2016.11.072

Lee YR, Kim J, Ahn WS (2013) Synthesis of metal-organic frameworks: a mini review. Korean J Chem Eng 309(30):1667-1680. https://doi.org/10.1007/S11814-013-0140-6

Li JR, Tao Y, Yu Q, Bu XH, Sakamoto H, Kitagawa S (2008) Selective gas adsorption and unique structural topology of a highly stable guest-free zeolite-type mof material with $\mathrm{N}$-rich chiral open channels. Chem A Eur J 14:2771-2776. https://doi.org/10. 1002/CHEM.200701447 
Li JR, Kuppler RJ, Zhou HC (2009) Selective gas adsorption and separation in metal-organic frameworks. Chem Soc Rev 38:14771504. https://doi.org/10.1039/B802426J

Li S, Chen Y, Pei X, Zhang S, Feng X, Zhou J, Wang B (2016) Water purification: adsorption over metal-organic frameworks. Chinese J Chem 34:175-185. https://doi.org/10.1002/CJOC.201500761

Li R, Chen T, Pan X (2021) Metal-organic-framework-based materials for antimicrobial applications. ACS Nano 15:3808-3848. https:// doi.org/10.1021/ACSNANO.0C09617

Liu W, Yin XB (2016) Metal-organic frameworks for electrochemical applications. TrAC Trends Anal Chem 75:86-96. https://doi.org/ 10.1016/J.TRAC.2015.07.011

Llewellyn P, Maurin G, Rouquerol J (2014) Adsorption by metalorganic frameworks. Adsorption by powders and porous solids. Elsevier, pp 565-610. https://doi.org/10.1016/B978-0-08097035-6.00014-0

Low JJ, Benin AI, Jakubczak P, Abrahamian JF, Faheem SA, Willis RR (2009) Virtual high throughput screening confirmed experimentally: Porous coordination polymer hydration. J Am Chem Soc 131:15834-15842. https://doi.org/10.1021/JA906 1344/SUPPL_FILE/JA9061344_SI_001.PDF

Lu X, Ye J, Zhang D, Xie R, Bogale RF, Sun Y, Zhao L, Zhao Q, Ning G (2014) Silver carboxylate metal-organic frameworks with highly antibacterial activity and biocompatibility. J Inorg Biochem 138:114-121. https://doi.org/10.1016/J.JINORGBIO. 2014.05.005

Luo F, Fan CB, Luo MB, Xiao Liu W, Zhu Y, Shou Zhi P, WenYuan X, Guo G-C (2014) Photoswitching CO and release in a photochromic diarylethene metal-organic framework. Chemie 126(35):9452-9455. https://doi.org/10.1002/ange.201311124

Lyndon R, Konstas K, Ladewig BP, Southon PD, Kepert PCJ, Hill MR (2013) Dynamic photo-switching in metal-organic frameworks as a route to low-energy carbon dioxide capture and release. Angew Chemie Int Ed 52:3695-3698. https://doi.org/ 10.1002/ANIE.201206359

Ma X, Chai Y, Li P, Wang B (2019) Metal-organic framework films and their potential applications in environmental pollution control. Acc Chem Res 52:1461-1470. https://doi.org/10.1021/ ACS.ACCOUNTS.9B00113

Mao Y, Li J, Cao W, Ying Y, Hu P, Liu Y, Sun L, Wang H, Jin C, Peng X (2014) General incorporation of diverse components inside metal-organic framework thin films at room temperature. Nat Commun 51(5):1-9. https://doi.org/10.1038/ncomms6532

Martín-Betancor K, Aguado S, Rodea-Palomares I, Tamayo-Belda M, Leganés F, Rosal R, Fernández-Piñas F (2017) Co, Zn and Ag-MOFs evaluation as biocidal materials towards photosynthetic organisms. Sci Total Environ 595:547-555. https://doi. org/10.1016/J.SCITOTENV.2017.03.250

Mba IE, Nweze EI (2021) Nanoparticles as therapeutic options for treating multidrug-resistant bacteria: research progress, challenges, and prospects. World J Microbiol Biotechnol 37:1-30. https://doi.org/10.1007/S11274-021-03070-X/TABLES/5

Min T, Sun X, Zhou L, Du H, Zhu Z, Wen Y (2021) Electrospun pullulan/PVA nanofibers integrated with thymol-loaded porphyrin metal-organic framework for antibacterial food packaging. Carbohydr Polym 270:118391. https://doi.org/10.1016/J. CARBPOL.2021.118391

Mueller U, Schubert M, Teich F, Puetter H, Schierle-Arndt K, Pastré J (2006) Metal-organic frameworks-prospective industrial applications. J Mater Chem 16:626-636. https://doi.org/ 10.1039/B511962F

Nagarajan V, Kizhaeral SS, Subramanian M, Rajendran S, Ranjan J (2021) Encapsulation of a volatile biomolecule (hexanal) in cyclodextrin metal-organic frameworks for slow release and its effect on preservation of mangoes. ACS Food Sci Technol 1(10):1936-44
Neves MIS, Gkaniatsou E, Nouar F, Pinto ML, SERRE C (2021) MOF industrialization: a complete assessment of production costs. Faraday Discus 231:326-341. https://doi.org/10.1039/D1FD00018G

Nong W, Wu J, Ghiladi RA, Guan Y (2021) The structural appeal of metal-organic frameworks in antimicrobial applications. Coordination Chem Rev 442:214007. https://doi.org/10.1016/j.ccr. 2021.214007

Ouyang H, Chen N, Chang G, Zhao X, Sun Y, Chen S, Zhang H, Yang D (2018) Selective capture of toxic selenite anions by bismuth-based metal-organic frameworks. Angew Chemie 130:13381-13385. https://doi.org/10.1002/ANGE.201807891

Pandiselvam R, Subhashini S, Banuu Priya EP, Kothakota A, Ramesh SV, Shahir S (2019) Ozone based food preservation: a promising green technology for enhanced food safety. Ozone Sci Eng 41(1): 17-34

Pang M, Cairns AJ, Liu Y, Belmabkhout Y, Zeng HC, Eddaoudi M (2012) Highly monodisperse M III-based soc -MOFs ( $\mathrm{M}=$ in and $\mathrm{Ga}$ ) with cubic and truncated cubic morphologies. J Am Chem Soc 134:13176-13179. https://doi.org/10.1021/JA304 9282/SUPPL_FILE/JA3049282_SI_001.PDF

Perry JJ, Perman JA, Zaworotko MJ (2009) Design and synthesis of metal-organic frameworks using metal-organic polyhedra as supermolecular building blocks. Chem Soc Rev 38:1400-1417. https://doi.org/10.1039/B807086P

Pettinari C, Pettinari R, Di Nicola C, Tombesi A, Scuri S, Marchetti F (2021) Antimicrobial MOFs. Coord Chem Rev 446:214121. https://doi.org/10.1016/J.CCR.2021.214121

Pnevskaya AY, Bugaev AL, Tereshchenko AA, Soldatov AV (2021) Experimental and Theoretical Investigation of Ethylene and 1-MCP Binding Sites in HKUST-1 Metal-Organic Framework. J Phys Chem C 125:22295-22300. https://doi.org/10.1021/ACS. JPCC.1C06503/SUPPL_FILE/JP1C06503_SI_001.PDF

Qazvini OT, Babarao R, Telfer SG (2021) Selective capture of carbon dioxide from hydrocarbons using a metal-organic framework. Nature Commu 12:197. https://doi.org/10.1038/ s41467-020-20489-2

Ramanayaka S, Vithanage M, Sarmah A, An T, Kim KH, Ok YS (2019) Performance of metal-organic frameworks for the adsorptive removal of potentially toxic elements in a water system: a critical review. RSC Adv 9:34359-34376. https://doi.org/10.1039/ C9RA06879A

Restuccia D, Spizzirri UG, Parisi OI, Cirillo G, Curcio M, Iemma F, Puoci F, Vinci G, Picci N (2010) New EU regulation aspects and global market of active and intelligent packaging for food industry applications. Food Control 21:1425-1435. https://doi. org/10.1016/J.FOODCONT.2010.04.028

Rieth AJ, Dincă M (2017) Moisture farming with metal-organic frameworks. Chem 2:757-759. https://doi.org/10.1016/J.CHEMPR. 2017.05.017

Rocío-Bautista Priscilla, Taima-Mancera Iván, Pasán Jorge, Pino Verónica (2019) Metal-organic frameworks in green analytical chemistry. Separations 6(3):33. https://doi.org/10.3390/separ ations6030033

Rojas S, Arenas-Vivo A, Horcajada P (2019) Metal-organic frameworks: a novel platform for combined advanced therapies. Coordination Chem Rev 388:202-226. https://doi.org/10.1016/j.ccr. 2019.02.032

Sajid M (2016) Toxicity of nanoscale metal organic frameworks: a perspective. Environ Sci Pollut Res 2315(23):14805-14807. https:// doi.org/10.1007/S11356-016-7053-Y

Seyedpour SF, Arabi Shamsabadi A, Khoshhal Salestan S, Dadashi Firouzjaei M, Sharifian GhM, Rahimpour A, Akbari AF, Shirzad Kebria M, reza., Elliott, MA; Tiraferri, A. (2020) Tailoring the biocidal activity of novel silver-based metal azolate frameworks. ACS Sustain. Chem Eng 8:7588-99 
Shams S, Ahmad W, Memon AH, Shams S, Wei Y, Yuan Q, Liang H (2020) $\mathrm{Cu} / \mathrm{H} 3 \mathrm{BTC}$ MOF as a potential antibacterial therapeutic agent against Staphylococcus aureus and Escherichia coli. New J Chem 44:17671-17678. https://doi.org/10.1039/D0NJ04120C

Sharanyakanth PS, Radhakrishnan M (2020) Synthesis of metalorganic frameworks (MOFs) and its application in food packaging: a critical review. Trends Food Sci Technol 104:102-116. https://doi.org/10.1016/J.TIFS.2020.08.004

Shen M, Forghani F, Kong X, Liu D, Ye X, Chen S, Ding T (2020) Antibacterial applications of metal-organic frameworks and their composites. Compr Rev Food Sci Food Saf 19:1397-1419. https://doi.org/10.1111/1541-4337.12515

Silva-Weiss A, Ihl M, Sobral PJA, Gómez-Guillén MC, Bifani V (2013) Natural additives in bioactive edible films and coatings: functionality and applications in foods. Food Eng Rev 4:200-216. https:// doi.org/10.1007/S12393-013-9072-5

Sindoro M, Jee AY, Granick S (2013) Shape-selected colloidal MOF crystals for aqueous use. Chem Commun 49:9576-9578. https:// doi.org/10.1039/C3CC45935G

Singh Ram, Geetanjali (2018) Metal organic frameworks for drug delivery. Applications of nanocomposite materials in drug delivery. Elsevier, pp 605-617. https://doi.org/10.1016/B978-0-12813741-3.00026-1

Singh S, Gaikwad KK, Lee YS (2019) Development and application of a pyrogallic acid-based oxygen scavenging packaging system for shelf life extension of peeled garlic. Sci Hortic 256:108548. https://doi.org/10.1016/j.scienta.2019.108548

Singh AK, Ramakanth D, Kumar A, Lee YS, Gaikwad KK (2021a) Active packaging technologies for clean label food products: a review. Food Measure 15:4314-4324. https://doi.org/10.1007/ s11694-021-01024-3

Singh G, Singh S, Kumar B, Gaikwad KK (2021b) Active barrier chitosan films containing gallic acid based oxygen scavenger. Food Measure 15(1):585-593. https://doi.org/10.1007/ s11694-020-00669-w

Singh S, Maji PK, Lee YS, Gaikwad KK (2021c) Applications of gaseous chlorine dioxide for antimicrobial food packaging: a review. Environ Chem Lett 19:253-270. https://doi.org/10.1007/ s10311-020-01085-8

Song Z, Wu Y, Cao Q, Wang H, Wang X, Han H, Song ZY, Wu Y, Han HY, Cao Q, Wang XR, Wang HJ (2018) pH-Responsive, lighttriggered on-demand antibiotic release from functional metalorganic framework for bacterial infection combination therapy. Adv Funct Mater 28:1800011. https://doi.org/10.1002/ADFM. 201800011

Stock N, Biswas S (2011) Synthesis of metal-organic frameworks (MOFs): routes to various MOF topologies, morphologies, and composites. Chem Rev 112:933-969. https://doi.org/10.1021/ CR200304E

Sultana A, Luo H, Ramakrishna S (2021) Harvesting of antimicrobial peptides from insect (hermetia illucens) and its applications in the food packaging. Appl Sci. https://doi.org/10.3390/APP11 156991

Sun L, Li L, An X, Qian X (2021) Nano-metal organic framework for enhanced mechanical, flame retardant and ultraviolet-blue light shielding properties of transparent cellulose-based bioplastics. Polymers 13(15):2433. https://doi.org/10.3390/polym13152433

Tu R, Zhang W, Zhang J, Wang M, Zhang F, Yang K, Li J, Pan H, Bernards MT, Xie P, He Y, Shi Y (2021) Squarate-calcium metalorganic framework for molecular sieving of co2 from flue gas with high water vapor resistance. Energy Fuels 35:13900-13907. https://doi.org/10.1021/ACS.ENERGYFUELS.1C01642

Valdés A, Mellinas AC, Ramos M, Garrigós MC, Jiménez A (2014) Natural additives and agricultural wastes in biopolymer formulations for food packaging. Front Chem 2:6. https://doi.org/10. 3389/FCHEM.2014.00006/BIBTEX
Vlasova EA, Naidenko EV, Gainulina ET, Vakaryuk DS (2018) Metalorganic frameworks as sorbents for purification of vegetable oils. Russian J App Chem 91(3):524-528. https://doi.org/10.1134/ S1070427218030278

Valdés A, Mellinas AC, Ramos M, Burgos N, Jiménez A, Garrigós MC (2015) Use of herbs, spices and their bioactive compounds in active food packaging. RSC Adv 5:40324-40335. https://doi. org/10.1039/C4RA17286H

Vikrant K, Kumar V, Kim KH, Kukkar D (2017) Metal-organic frameworks (MOFs): potential and challenges for capture and abatement of ammonia. J Mater Chem A 5:22877-22896. https://doi. org/10.1039/C7TA07847A

Vilela C, Kurek M, Hayouka Z, Röcker B, Yildirim S, Antunes MDC, Nilsen-Nygaard J, Pettersen MK, Freire CSR (2018) A concise guide to active agents for active food packaging. Trends Food Sci Technol 80:212-222. https://doi.org/10.1016/J.TIFS.2018.08.006

Wang H, Rassu P, Wang X, Li H, Wang X, Wang X, Feng X, Yin A, Li P, Jin X, Chen S-L, Ma X, Wang B (2018) An iron-containing metal-organic framework as a highly efficient catalyst for ozone decomposition. Angew Chemie 130:16654-16658. https://doi. org/10.1002/ANGE.201810268

Wang Y, Hu Y, He Q, Yan J, Xiong H, Wen N, Cai S, Peng D, Liu Y, Liu Z (2020) Metal-organic frameworks for virus detection. Biosens Bioelectron 169:112604. https://doi.org/10.1016/J. BIOS.2020.112604

Willdigg JR, Helmann JD (2021) Mini review: bacterial membrane composition and its modulation in response to stress. Front Mol Biosci 8:338. https://doi.org/10.3389/FMOLB.2021.634438/ BIBTEX

Wyszogrodzka G, Marszałek B, Gil B, Dorożyński P (2016) Metalorganic frameworks: mechanisms of antibacterial action and potential applications. Drug Discover Today 21(6):10091018.https://doi.org/10.1016/j.drudis.2016.04.009

Xie BP, Chai JW, Fan C, Ouyang JH, Duan WJ, Sun B, Chen J, Yuan LX, Xu XQ, Chen JX (2020) Water-stable silver-based metalorganic frameworks of quaternized carboxylates and their antimicrobial activity. ACS Appl Bio Mater 3:8525-8531. https://doi. org/10.1021/ACSABM.0C00896/SUPPL_FILE/MT0C00896_ SI_003.PDF

Xu W, Yaghi OM (2020) Metal-organic frameworks for water harvesting from air, anywhere anytime. ACS Cent Sci 6:1348-1354. https://doi.org/10.1021/ACSCENTSCI.0C00678

Xu Y-P, Tian Z-J, Wang S-J, Hu Y, Wang L, Wang B-C, Ma Y-C, Hou L, Yu J-Y, Lin L-W, Xu Y-P, Tian Z-J, Wang L, Wang B-C, Wang JS, Hu Y, Ma Y-C, Hou L, Yu J-Y, Lin L-W (2006) Microwaveenhanced ionothermal synthesis of aluminophosphate molecular sieves. Angew Chemie Int Ed 45:3965-3970. https://doi.org/10. 1002/ANIE.200600054

Yaghi OM, O'Keeffe M, Ockwig NW, Chae HK, Eddaoudi M, Kim J (2003) Reticular synthesis and the design of new materials. Nat. https://doi.org/10.1038/nature01650

Yildirim S, Röcker B, Pettersen MK, Nilsen-Nygaard J, Ayhan Z, Rutkaite R, Radusin T, Suminska P, Marcos B, Coma V (2018) Active packaging applications for food. Compr Rev Food Sci Food Saf 17:165-199. https://doi.org/10.1111/1541-4337.12322

Yuan S, Feng L, Wang K, Pang J, Bosch M, Lollar C, Sun Y, Qin J, Yang X, Zhang P, Wang Q, Zou L, Zhang Y, Zhang L, Fang Y, Li J, Zhou H-C, Yuan S, Feng L, Wang K, Pang J, Bosch M, Lollar C, Sun Y, Qin J, Yang X, Zhang P, Wang Q, Zou L, Zhang Y, Zhang L, Fang Y, Li J, Zhou H (2018) Stable metalorganic frameworks: design, synthesis, and applications. Adv Mater 30:1704303. https://doi.org/10.1002/ADMA.201704303

Zhang ZH, Zhang QQ, Feng S, Hu ZJ, Chen SC, Chen Q, He MY (2013) Fluorinated metal-organic frameworks of 1,4-bis(1,2,4triazol-1-ylmethyl)-2,3,5,6-tetrafluorobenzene: synergistic 
interactions of ligand isomerism and counteranions. Dalt Trans 43:646-655. https://doi.org/10.1039/C3DT52211C

Zhang B, Luo Y, Kanyuck K, Bauchan G, Mowery J, Zavalij P (2016) Development of metal-organic framework for gaseous plant hormone encapsulation to manage ripening of climacteric produce. $\mathrm{J}$ Agric Food Chem 64:5164-5170. https://doi.org/10.1021/ACS. JAFC.6B02072

Zhang Y, Lin Z, He Q, Deng Y, Wei F, Xu C, Fu L, Lin B (2022) Enhanced aqueous stability and long-acting antibacterial of silver-based MOFs via chitosan-crosslinked for fruit fresh-keeping. Appl Surf Sci 571:151351. https://doi.org/10.1016/J.APSUSC. 2021.151351
Zhao J, Wei F, Xu W, Han X (2020) Enhanced antibacterial performance of gelatin/chitosan film containing capsaicin loaded MOFs for food packaging. Appl Surf Sci 510:145418. https:// doi.org/10.1016/J.APSUSC.2020.145418

Publisher's Note Springer Nature remains neutral with regard to jurisdictional claims in published maps and institutional affiliations. 